\title{
Recent applications of rare-earth metal(III) triflates in cycloaddition and cyclization reactions
}

\author{
Uladzimir (Vladimir) Ladziata \\ Discovery Chemistry, Bristol-Myers Squibb Co., 311 Pennington-Rocky Hill Rd., \\ Pennington, NJ 08534, U.S.A. \\ E-mail: vladimir.ladziata@bms.com
}

DOI: http://dx.doi.org/10.3998/ark.5550190.0015.100

\begin{abstract}
Rare-earth metal(III) triflates are extremely mild, efficient and water-tolerable Lewis acid catalysts for a wide range of organic transformations. Rare-earth metal triflates retain activity even in the presence of multiple Lewis bases containing oxygen, nitrogen, sulfur and phosphorus atoms, and can be easily recovered and reused without any loss of catalytic activity. This review summarizes recent developments and highlights key applications of these unique Lewis acids in cycloaddition and cyclization reactions.
\end{abstract}

Keywords: Rare-earth triflates, lanthanide triflates, cyclization, cycloaddition, Lewis acid, catalysis

\section{Table of Contents}

1. Introduction

2. Cycloadditions and Cyclizations

2.1 Carbon Diels-Alder reactions

2.2 Hetero-Diels-Alder reactions

$2.3[3+2]$ Cycloadditions and related processes

$2.4[1,5]-\mathrm{H}$ Shift/ring closure reactions

2.5 Radical cyclizations

2.6 Other cyclization reactions

3. Conclusions

4. Acknowledgements

References and Notes 


\section{Introduction}

In the last two decades, the application of lanthanide triflates $\mathrm{Ln}(\mathrm{OTf})_{3}(\mathrm{Ln}=\mathrm{La}, \mathrm{Ce}, \mathrm{Pr}, \mathrm{Nd}, \mathrm{Sm}$, $\mathrm{Eu}, \mathrm{Gd}, \mathrm{Tb}, \mathrm{Dy}, \mathrm{Ho}, \mathrm{Er}, \mathrm{Tm}, \mathrm{Yb}, \mathrm{Lu}$; OTf $=\mathrm{CF}_{3} \mathrm{SO}_{3}{ }^{-}$) in organic synthesis has experienced immense growth. Lanthanide(III) triflates, together with chemically similar triflates of pseudolanthanides Sc(III) and Y(III), have proven to be mild, stable Lewis acids that are known for their oxophilicity ${ }^{1}$ and stability in the presence of water ${ }^{2}$, making them water-compatible Lewis acids particularly suitable for green chemistry applications. These rare-earth metal(III) triflates $\left[\mathrm{M}(\mathrm{OTf})_{3}\right]$ remain active in the presence of a wide variety of Lewis bases, thereby providing exceptional functional group tolerance and in many cases obviating the need for protecting groups. $\mathrm{M}(\mathrm{OTf})_{3}$ have demonstrated high chemo- and regioselectivity, and exceptional conversions for a number of challenging synthetic transformations. Moreover, unlike traditional Lewis acids such as $\mathrm{BF}_{3}, \mathrm{AlCl}_{3}, \mathrm{TiCl}_{4}$, etc., catalytic usage, recovery and reuse are possible for $\mathrm{M}(\mathrm{OTf})_{3}$ reagents. Their low toxicity, environmentally benign character, moderate cost and ease of availability make these reagents attractive for the synthetic community. Intriguingly, a recent report demonstrated that lanthanides are an essential cofactor for methanol dehydrogenase in a volcanic methanotropic bacterium, thereby underscoring that lanthanides' superior catalytic properties are used in biological systems. ${ }^{3}$

Rare-earth elements(III) triflates are readily prepared from the corresponding oxides $\left(\mathrm{M}_{2} \mathrm{O}_{3}\right)$ or chlorides $\left(\mathrm{MCl}_{3}\right)$ in an aqueous trifluoromethanesulfonic acid. ${ }^{4,5}$ Since their introduction into organic synthesis in 1987 by Frosberg and co-workers, ${ }^{6}$ and subsequent pioneering studies by Kobayashi's research group, ${ }^{7-9}$ the field of $\mathrm{Sc}(\mathrm{OTf})_{3}, \mathrm{Y}(\mathrm{OTf})_{3}$ and $\mathrm{Ln}(\mathrm{OTf})_{3}$-catalyzed reactions has seen evergrowing interest with several reviews covering the major aspects of this chemistry published to date. ${ }^{10-15}$ Therefore, the purpose of the present review is not to summarize all the efforts in the area comprehensively, but instead highlight a select number of important applications of rare-earth metal triflates in cyclization and cycloaddition reactions reported over the last five years, up to the first three quarters of 2013.

\section{Cycloadditions and Cyclizations}

Cycloaddition and cyclization processes, exemplified by Diels-Alder (DA), hetero-Diels-Alder (HDA) reactions and Huisgen cycloaddition, are of great importance in organic chemistry, since they provide distinct reactivity and selectivity patterns, and offer rapid entries into complex cyclic structures bearing multiple stereocenters. ${ }^{16,17}$ Lewis acids, including lanthanide(III) triflates, were shown to effectively catalyze cycloaddition reactions in general, allowing for lower reaction temperatures, faster times and cleaner conversions. ${ }^{18}$ Apart from possessing high oxophilicity and moisture tolerability, the uniqueness of rare-earth metal(III) triflates with regards to cycloaddition reactions consists of their ability to offer exceptionally high coordination numbers, allowing for extremely organized transitions states, and consequently providing excellent stereoselectivities. ${ }^{19,20}$ 
In this review, interesting examples of strategic utilization of rare-earth metal triflates for cycloaddition/cyclization reactions published in recent years will be highlighted, with the emphasis on advantages over conventional Lewis acids. A comprehensive treatment of all recently recorded cyclizations/cycloadditions utilizing rare-earth metal triflates is beyond the scope of this review. However, the author has attempted to provide broad coverage of diverse cyclization reaction types with the hope of reinforcing significant research activity in the area of M(III) Lewis acid catalysis. The review is organized into six main portions: carbon Diels-Alder reactions, hetero-Diels-Alder reactions, [3+2], [3+3] and [4+3] cycloadditions, hydride shift/ring closure sequences, radical cyclization processes and miscellaneous cyclization reactions.

\subsection{Carbon Diels-Alder Reactions}

$\mathrm{M}(\mathrm{OTf})_{3}$ have been shown to be effective catalysts for Diels-Alder reactions of various sensitive dienes and dienophiles, ${ }^{21-23}$ and first chiral Sc(III) and Yb(III)-based catalytic systems for DA reactions were disclosed by Kobayashi and co-workers in the 1990 s. $^{24,25}$ One interesting example of asymmetric DA reaction involving Danishefsky-type dienes 1 was reported by Nishida's group. $^{26,27}$ Specifically, complexes of $\mathrm{Yb}(\mathrm{OTf})_{3}$, axially chiral ligands BINAMIDE and BINUREA and an amine catalyzed the DA reaction in a highly diastereo- and enantio-selective manner to provide densely functionalized chiral cyclohexenes 3. Notably, utilization of a lanthanide triflate was the key in promoting the desired reaction without any appreciable decomposition of either substrate $\mathbf{2}$ or the reaction product $\mathbf{3}$. The reaction is quite general, and can tolerate a variety of substituents on dienophile $\mathbf{2}$, including aryl, alkenyl, halogens and ester moieties. The yield/enantioselectivity was lower in the case of sterically hindered dienophiles 2 bearing bulky groups (Scheme 1).

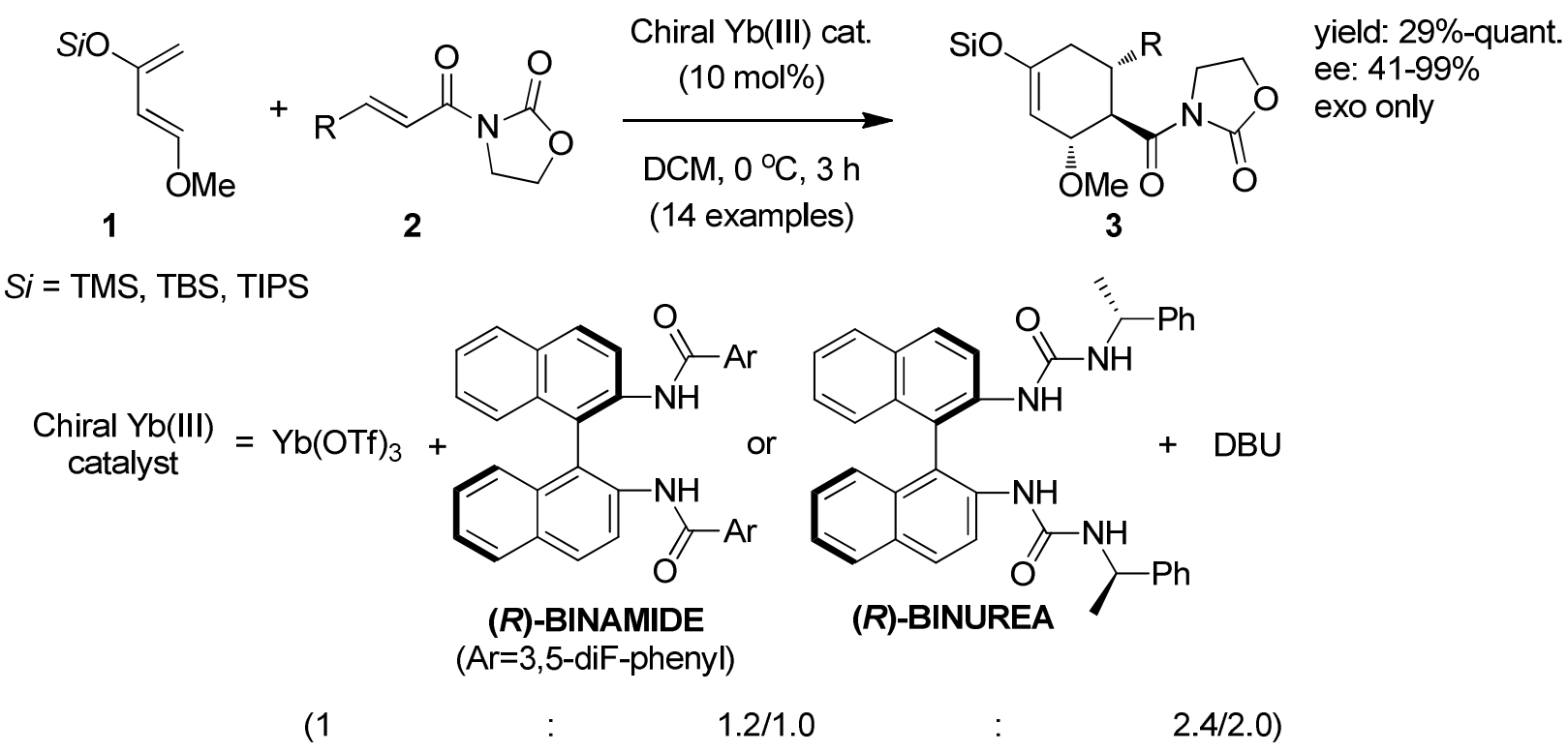

Scheme 1. Asymmetric Diels-Alder reaction catalyzed by Yb(III) complexes. 
This operationally convenient and robust protocol was subsequently employed as a key step in the asymmetric total synthesis of (+)- and (-)-platyphyllide. ${ }^{28}$ As a result, the absolute configuration of the natural (-)-form was revised to be the $(6 S, 7 S)$-enantiomer.

A similar bis-thiourea 6-based asymmetric catalytic system disclosed by the same research group three year later in 2013 utilizes holmium(III) Lewis acid instead of the ytterbium(III) protocol described above. The reported [4+2]-cycloaddition of silyloxyvinylindoles $\mathbf{4}$ provides an expedient stereoselective entry into hydrocarbazoles 7 (Scheme 2), as well as hydroindoles and hydrobenzofurans. ${ }^{29}$ The obtained chiral cycloadducts could serve as potential synthetic intermediates for Strychnos alkaloids.<smiles>[R]C=CC(=O)N1CCOC1=O</smiles>

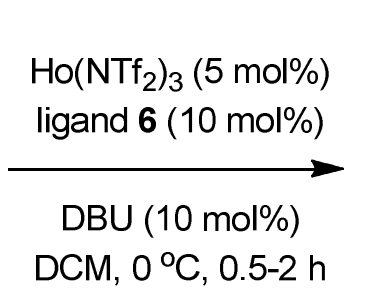

(11 examples)

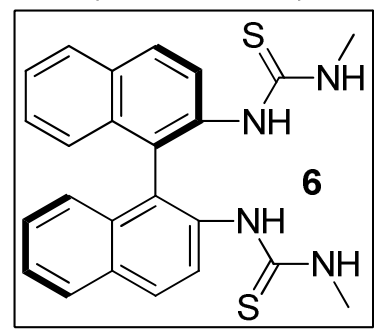<smiles>[R]C1CC(O[AsH2])=C2c3ccccc3N(S(=O)(=O)O)[C@@]2(C)[C@H]1C(=O)N1CCOC1=O</smiles>

yield: $90-99 \%$. ee: $75-94 \%$ exo only

Scheme 2. Diels-Alder reaction of 3-siloxyvinylindole 4.

It has been demonstrated that $\mathrm{Sc}(\mathrm{OTf})_{3}$ can catalyze generation and successive aromatization of isobenzofuran from $o$-dicarbonylbenzenes $\mathbf{8}$ to yield the corresponding naphthalene derivatives $\mathbf{1 0}$ (Scheme 3$).{ }^{30} \mathrm{Sc}(\mathrm{OTf})_{3}$ catalyzed both hydrosilylation and

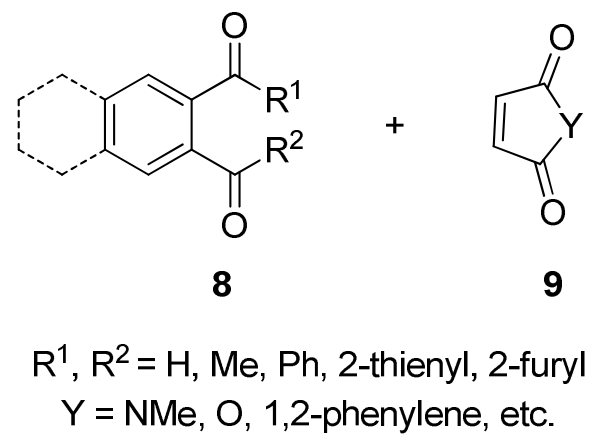

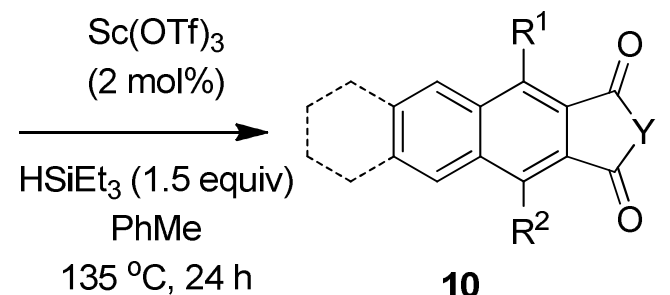

(11 examples)

yields: $18-78 \%$

Scheme 3. Preparation of naphthalene derivatives 10. 
dehydration of an intermediate Diels-Alder adduct, and Sc/Amberlyst-15 recyclable catalyst was shown to be efficient for the reaction. The nature of $\mathrm{R}^{1}$ and $\mathrm{R}^{2}$ groups affected the yield of the reaction. In correlation with the hydrosilylation propensity, acetyl derivatives were less reactive, while formyl and aroyl/heteroaroyl groups provided good conversions.

Enantioselective $\mathrm{Yb}(\mathrm{OTf})_{3} /$ Pybox-catalyzed Diels-Alder reactions with enhanced exo selectivity were studied by Sibi and co-workers. ${ }^{31}$ The nature of a pyrazolidinone auxiliary and a Pybox ligand greatly affected the yield of exo-adduct 13 (Scheme 4). It is noteworthy that the $\mathrm{Sc}(\mathrm{OTf})_{3}$-catalyzed reaction, as opposed to employing $\mathrm{Yb}(\mathrm{OTf})_{3}$ or $\mathrm{Y}(\mathrm{OTf})_{3}$, led to endoselective cycloadditions.

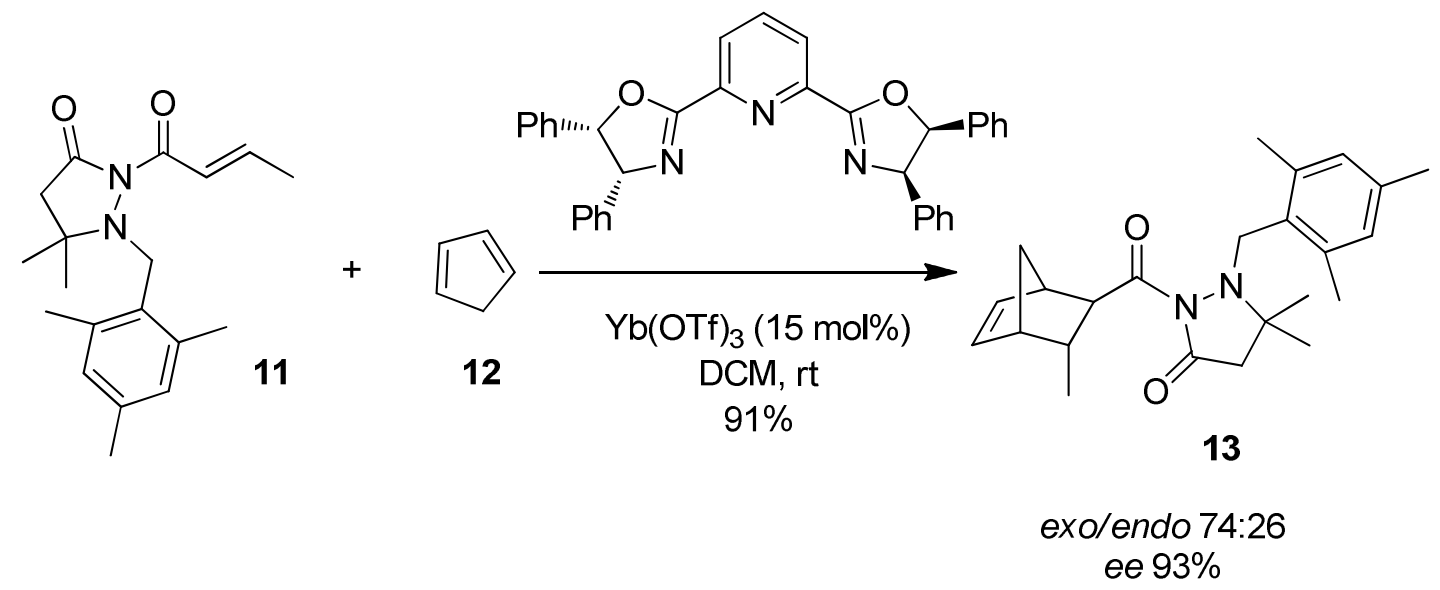

Scheme 4. Exo-selective Diels-Alder reaction.

An interesting $\mathrm{Sc}(\mathrm{OTf})_{3}$-mediated Diels-Alder reaction between biomass-derived 2,5dimethylfuran 14 and acrolein 15 to produce $p$-xylene 17 was reported by Toste et al. in 2011 (Scheme 5). ${ }^{32}$ The described route, although not being immediately practical, demonstrated the possibility of realizing a completely bio-renewable approach to PET precursor $p$-xylene utilizing Sc(III) Lewis acid.

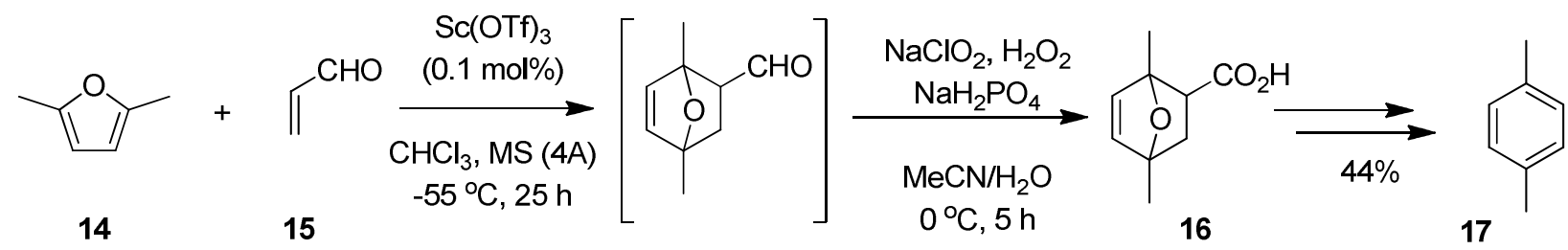

yields: $77 \%$

over 2 steps

Scheme 5. Bio-renewable approach to $p$-xylene 17 using $\mathrm{Sc}(\mathrm{OTf})_{3}$. 


\subsection{Hetero-Diels-Alder reactions}

The hetero-Diels-Alder reaction has attracted significant attention over the past decades as a unique method for the assembly of complex heterocycles in a convergent and regioselective fashion, generally from simple, readily available building blocks. ${ }^{33,34}$ Among various synthetic methodologies available, asymmetric hetero-Diels-Alder has emerged as one of the most powerful tools for the construction of complex six-membered heterocyclic systems found in the plethora of natural products and active pharmaceutical ingredients. ${ }^{35,36}$ As was the case for DA reactions, rare-earth metal(III) triflates have also been successfully employed to promote heteroDiels-Alder reactions. ${ }^{10-15}$ Below are notable examples of $\mathrm{M}(\mathrm{OTf})_{3}$-catalyzed HDA reactions published in the last five years.

In an effort to access polyhydroxylated indolizine scaffolds, Yang and co-workers studied asymmetric aza-Diels-Alder reaction of pyrrolidine imine $\mathbf{1 8}$ with an excess of Danishefsky's diene 1 under various reaction conditions (Table 1). ${ }^{37}$ Conventional Lewis acids like $\mathrm{BF}_{3}-\mathrm{Et}_{2} \mathrm{O}$, $\mathrm{ZnCl}_{2}$ and $\mathrm{AlCl}_{3}$, gave disappointing results, expressed in either unsatisfactory diastereomeric ratios or poor yields. Gratifyingly, $\mathrm{Yb}(\mathrm{OTf})_{3}$ catalyzed the reaction with excellent yields and diastereoselectivity (Table 1, entries 7, 8). This $\mathrm{Yb}$ (III)-mediated methodology allowed rapid and highly selective entry into stereochemically rich indolizine enaminones, and was successfully utilized in a concise syntheses of (+)-/(-)-lentiginosines and (-)-2-epi-stevamine. ${ }^{37}$

Table 1. Lewis acid catalysis of asymmetric aza-Diels-Alder reaction ${ }^{\mathrm{a}}$

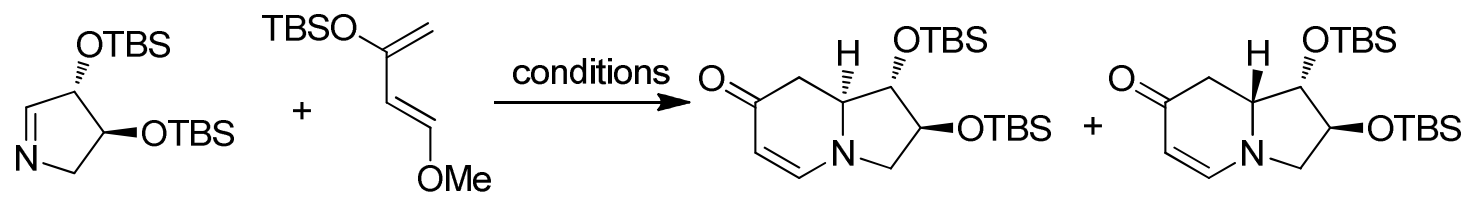

18

1

19

20

\begin{tabular}{ccccc}
\hline Entry & $\begin{array}{c}\text { Catalyst } \\
\text { (equiv.) }\end{array}$ & $\begin{array}{c}\mathrm{T} \\
\left({ }^{\circ} \mathrm{C}\right) / \text { solvent }\end{array}$ & Yield & $\mathrm{dr}^{\mathrm{b}}$ \\
\hline 1 & $\mathrm{ZnCl}_{2}(1.0)$ & $\begin{array}{l}-40 \text { to rt } / \\
\mathrm{THF}\end{array}$ & 36 & $1.9 / 1$ \\
2 & $\mathrm{ZnCl}_{2}(1.0)$ & $\begin{array}{l}-40 \text { to rt } / \\
\mathrm{PhMe}\end{array}$ & 43 & $1.2 / 1$ \\
3 & $\mathrm{ZnCl}_{2}(1.0)$ & $\begin{array}{l}-40 \text { to rt } / \\
\mathrm{DCM}\end{array}$ & 65 & $4 / 1$ \\
4 & $\mathrm{AlCl}_{3}(1.0)$ & $-40 / \mathrm{DCM}$ & 70 & $4.9 / 1$ \\
5 & $\mathrm{BF}_{3}-\mathrm{EtO}_{2}$ & $-40 / \mathrm{DCM}$ & $<15$ & n.d. \\
& $(1.0)$ & -40 to rt $/$ & $<15$ & n.d. \\
\hline
\end{tabular}


Table 1. Continue

\begin{tabular}{ccccc}
\hline Entry & $\begin{array}{c}\text { Catalyst } \\
(\text { equiv. })\end{array}$ & $\begin{array}{c}\mathrm{T} \\
\left({ }^{\circ} \mathrm{C}\right) / \text { solvent }\end{array}$ & Yield & $\mathrm{dr}^{\mathrm{b}}$ \\
\hline 7 & $\begin{array}{l}\text { Yb(OTf })_{3} \\
(1.0)\end{array}$ & $-40 / \mathrm{DCM}$ & 73 & $11 / 1$ \\
8 & $\begin{array}{l}\text { Yb(OTf })_{3} \\
(0.5)\end{array}$ & $\begin{array}{l}-40 \text { to } 0 / \\
\text { DCM }\end{array}$ & 73 & $11 / 1$ \\
\hline
\end{tabular}

${ }^{a}$ Preformed with 18 (1.0 equiv), 1 (1.0 equiv), and catalyst in anhydrous solvent for 3 h. ${ }^{b}$ Ratio 19/20, determined by ${ }^{1} \mathrm{H}-\mathrm{NMR}$.

Lanthanide triflates were employed by Wang and his group in the context of novel organocatalyst/metal Lewis acid bifunctional catalytic system to tackle a long-standing challenge of asymmetric inverse electron-demand hetero-Diels-Alder (IED/HDA) of cyclic ketones (Scheme 6). ${ }^{38}$ During the initial metal salt co-catalyst screen, $\mathrm{Cu}\left(\mathrm{SbF}_{6}\right)_{2}, \mathrm{Sc}(\mathrm{OTf})_{3}$ and $\mathrm{Eu}(\mathrm{fod})_{3}$ yielded exclusively an aldol side-product. On the other hand, $\mathrm{La}(\mathrm{OTf})_{3}, \mathrm{Y}(\mathrm{OTf})_{3}$ and $\mathrm{Yb}(\mathrm{OTf})_{3}$ produced the desired product 24; the latter catalyst $\mathrm{Yb}(\mathrm{OTf})_{3}$ was selected because of superior chemo-, diastereo- and enantioselectivity (Scheme 6). In terms of substrate scope, a wide range of ketones 21 and enones 22 reacted smoothly providing bicycles $\mathbf{2 4}$ with excellent diastereoand enantioselectivities and in high yields. Remarkably, no aldol side-product was detected for the majority of the reactions, except for heterocyclic ketones $\mathbf{2 1}(\mathrm{Y}=\mathrm{O}, \mathrm{S})$ and $\gamma$-3-nitrophenyl enone 22.<smiles>O=C1CC[Y]CC1</smiles>

21<smiles>[R]c1ccc(/C=C/C(=O)C([R])[R])cc1[R]</smiles>

22
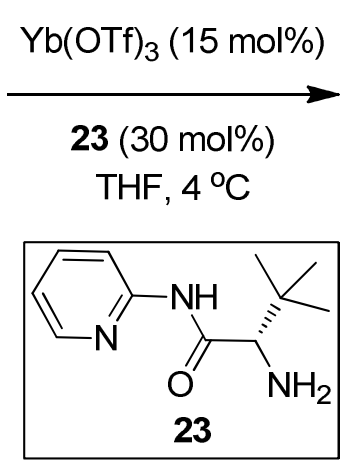

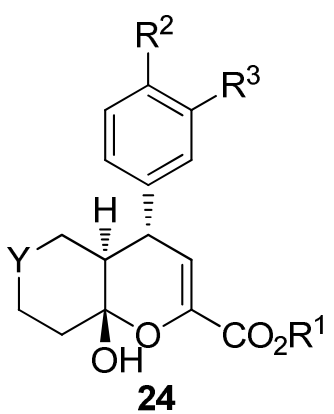

dr: $3: 1$ to $9: 1$ ee: $92-99 \%$ yield: $70-90 \%$

Scheme 6. Asymmetric IED/HDA with $\mathrm{Yb}(\mathrm{OTf})_{3}$ and primary amine ligand 23.

It is worth mentioning that only two endo diastereomers were observed during this heteroDiels-Alder reaction, despite the fact that three to four stereogenic centers were formed. The sense of asymmetric induction could be rationalized by assuming the formation of octahedral 
$\mathrm{Yb}$ (III)-diene complex 25 (Figure 1). The bulky tert-butyl group from the amine ligand $\mathbf{2 3}$ effectively shields the $R e$ face of the enamine, and enone approaches from the $S i$ face, to afford the product with the observed absolute configuration. ${ }^{38}$

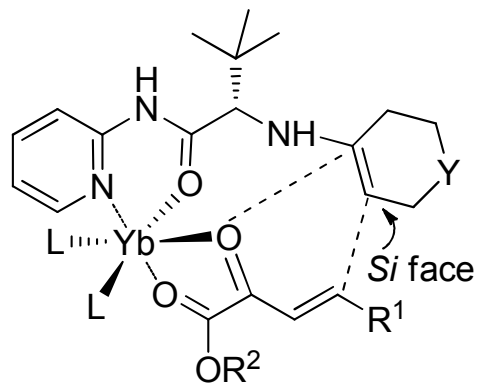

25

Figure 1. Proposed transition state.

An unprecedented $\operatorname{Er}(\mathrm{OTf})_{3}$-mediated hetero-Diels-Alder reaction of $\alpha, \beta$-unsaturated acid chlorides 26 with aromatic and heteroaromatic aldehydes 27 to give synthetically useful $\delta$ lactones 29 was developed by Peters and co-workers. ${ }^{39} \operatorname{Er}(\mathrm{OTf})_{3}$ was selected due to its considerably lower cost compared to other lanthanide triflates, and relatively small ionic radius favoring highly organized transition states. The generality of this cooperative bifunctional Lewis acid-Lewis base catalytic approach was demonstrated on a variety of substrates bearing methoxy-, trifluoromethyl-, halo-, and nitroaryl, as well as heteroaryl moieties (Scheme 7). It should be noted that electron-donating groups on aryl aldehydes $\mathbf{2 7}$ resulted in lower yields, while electron-withdrawing groups enhanced the reactivity.

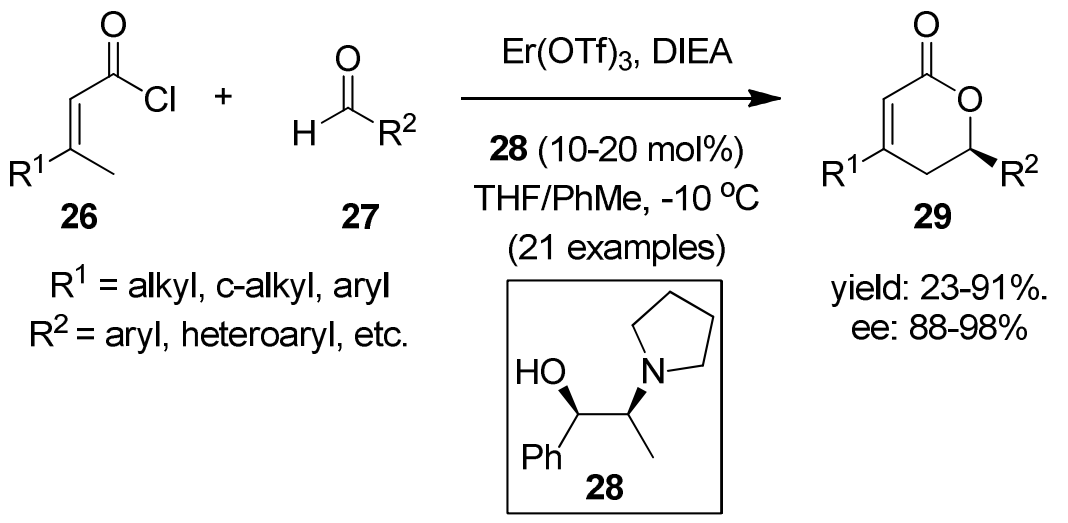

Scheme 7. HDA reaction leading to $\delta$-lactones 29.

Another application of $\operatorname{Er}(\mathrm{OTf})_{3}$ for a highly enantioselective synthesis of 3,4-dihydro- $2 \mathrm{H}$ pyrans 33 featuring remarkably low catalyst loading $(0.5-0.075 \mathrm{~mol} \%)$ was reported by Feng and co-workers in 2011. ${ }^{40}$ This protocol utilizes the highly efficient $\mathrm{N}, \mathrm{N}^{\prime}$-dioxide ligand 32, which putatively forms the $\left[(\mathbf{3 2})_{2} \operatorname{Er}(\mathrm{OTf})_{3}\right]$ complex as suggested by a positive non-linear effect. Initial 
metal salts screen revealed that traditional Lewis acids like $\mathrm{Fe}(\mathrm{III})$ and $\mathrm{Cu}(\mathrm{II})$ gave poor results, while $\mathrm{Ln}(\mathrm{III})$ triflates- $\operatorname{Er}(\mathrm{OTf})_{3}$ being the most efficient_- provided favorable conversion and enantioselectivity. A broad range of functional groups on $\beta, \gamma$-unsaturated $\alpha$-ketoesters 30 is tolerated. The reaction proceeds in $\mathrm{DCM}$ at $0{ }^{\circ} \mathrm{C}$, providing target products 33 in excellent chemical yields, as well as enantio- and diastereomeric excess, and could be scaled up to gram quantities with the same outstanding results (Scheme 8).

As was mentioned above, M(III)-based Lewis acids have exceptional affinities to carbonyl oxygens and carboxylates, thus allowing for extremely organized transition states for substrates bearing these moieties. This fact was utilized by Chi et al. in the course of developing highly enantioselective condensation of enals 34 with trifluoroketones 35 under N-heterocyclic carbene (NHC) catalysis (Scheme 9). ${ }^{41}$ The usage of $\mathrm{Sc}(\mathrm{OTf})_{3}$ as a Lewis acid co-catalyst resulted in a remarkable amplification of an otherwise weak chiral induction by enantiopure NHC 36.

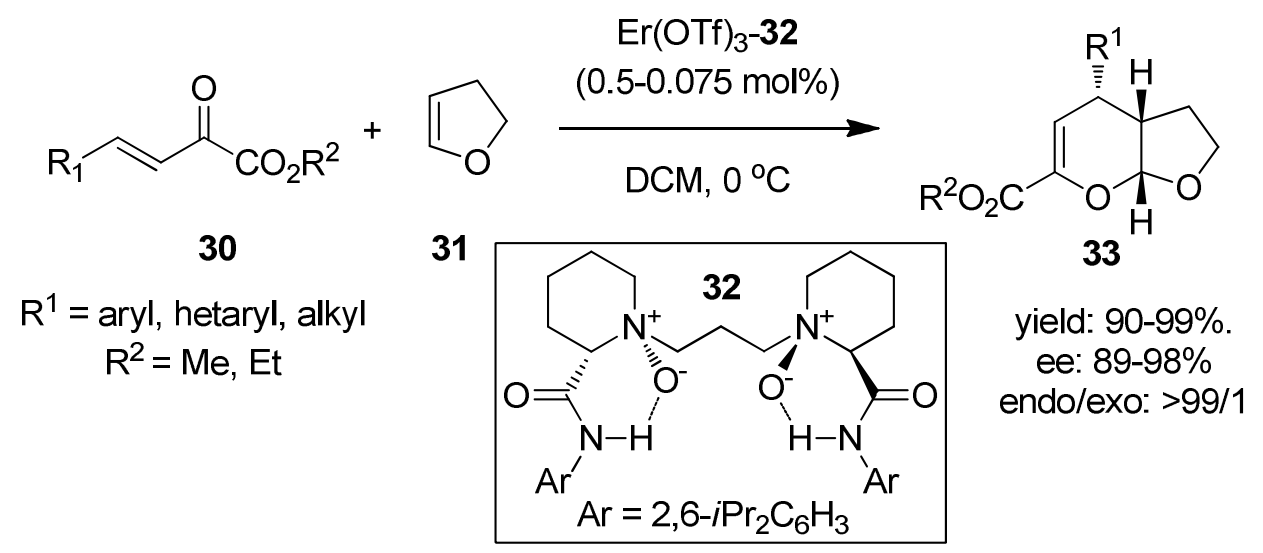

Scheme 8. Enantioselective HDA reaction of DHF 31 and $\beta, \gamma$-unsaturated $\alpha$-ketoesters 30.

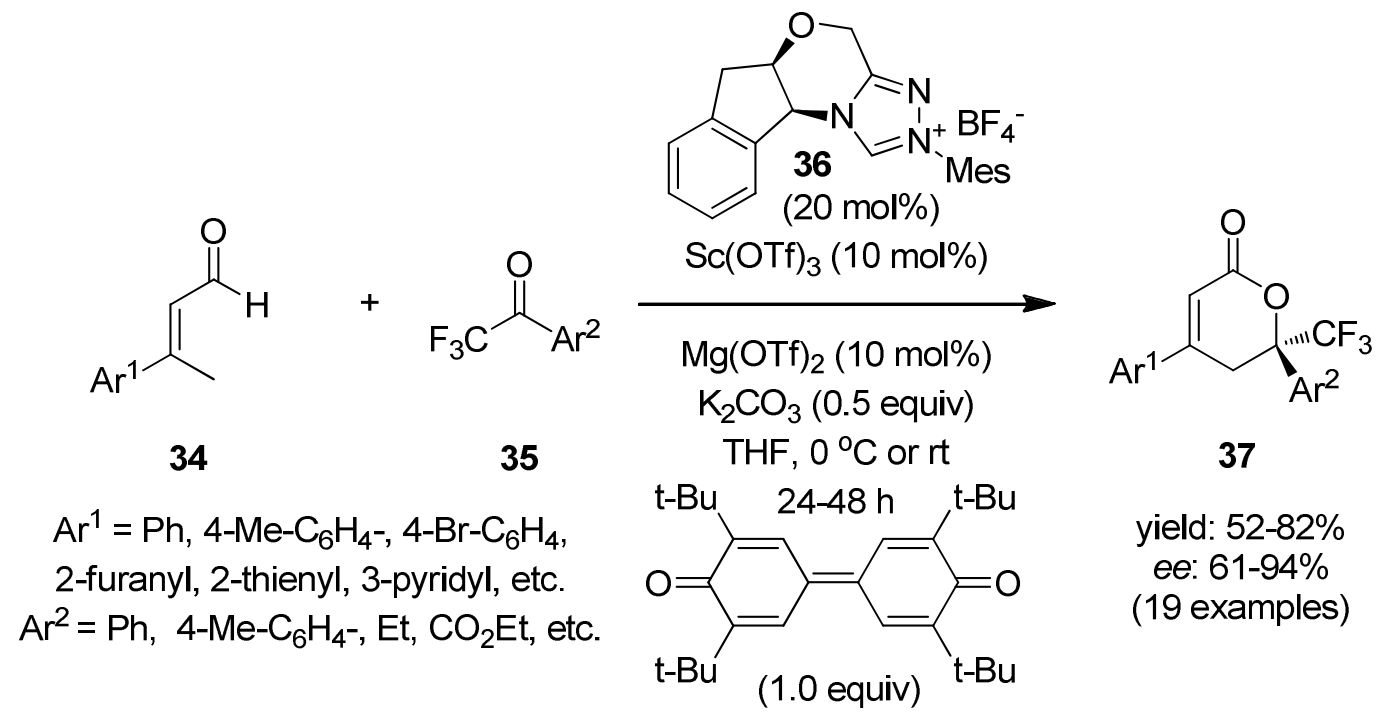

Scheme 9. $\mathrm{Sc}(\mathrm{OTf})_{3}-\mathrm{NHC}$ cooperative catalysis. 
In another report, Doyle and his group disclosed a $\mathrm{Sc}(\mathrm{OTf})_{3}$-catalyzed method for the preparation of tetrahydroquinolines and benzazepines via a Povarov reaction. ${ }^{42,43}$ Upon treatment with $\mathrm{Rh}_{2}(\mathrm{OAc})_{4}$, enoldiazoacetates 38 undergo dinitrogen extrusion, and the generated donoracceptor cyclopropenes react with imine counterparts 39 to afford target tetrahydroquinolines $\mathbf{4 0}$ in a highly regio- and stereoselective fashion (Scheme 10). ${ }^{44}$ Surveying a variety of Lewis and Brønsted acid catalysts identified $\mathrm{Sc}(\mathrm{OTf})_{3}$ as the catalyst of choice for this transformation. The reaction is quite general and provides excellent yields of Povarov products for both electrondonating and moderately electron-accepting groups on imine 39, as well as heteroaryl imines. However, in the case of a strongly electron-withdrawing nitro group the transformation proceeded with diminished efficiency. The obtained fused cyclopropane tetrahydroquinolines 40 upon treatment with TBAF could be further elaborated into $1 H$-benzazepine privileged structures 41 (Scheme 10).

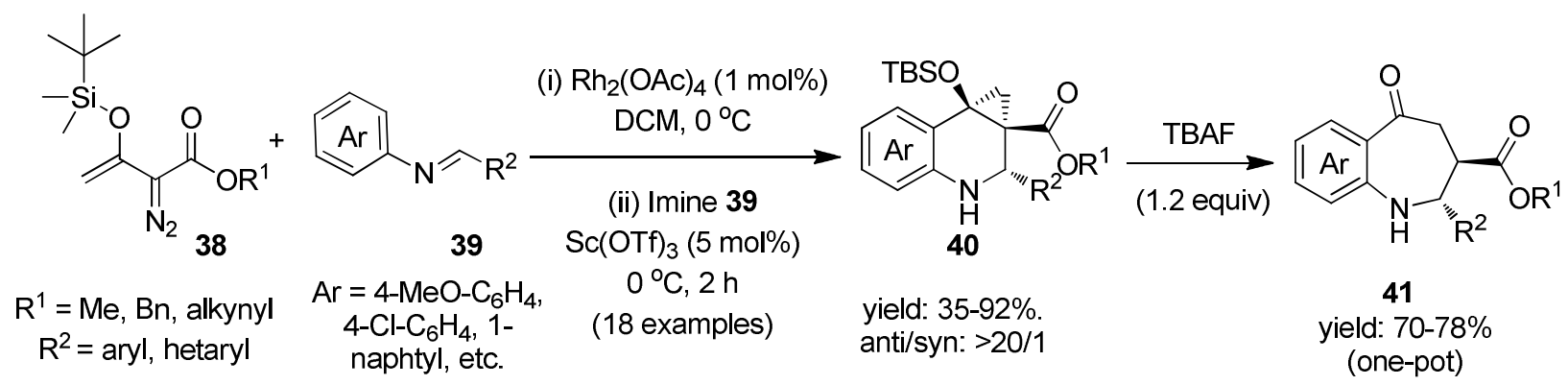

Scheme 10. $\mathrm{Sc}(\mathrm{OTf})_{3}$-promoted Povarov reaction and benzazepines synthesis.

A general, single-step, solventless procedure to access medicinally important 3-hydroxypyridine scaffold 47 via Kondrat'eva hetero-Diels-Alder reaction ${ }^{45}$ was reported by Renard et $a{ }^{46}$ While $\mathrm{Hf}(\mathrm{IV})$ and $\mathrm{Cu}(\mathrm{II})$ triflates were unsuccessfully explored for the transformation, $\mathrm{La}(\mathrm{III}), \mathrm{Sm}(\mathrm{III})$ and $\mathrm{Nd}(\mathrm{III})$ notably improved the reaction efficiency (Table 2).

The scope of the aforementioned $\mathrm{Nd}(\mathrm{III})$-catalyzed reaction is rather broad, and a wide range of substituents were tolerated on both oxazoles $\mathbf{4 5}$ and dienophile $\mathbf{4 6}$ components (Scheme 11). It should be noted that small substituents at position 5 of the oxazole $\mathbf{4 5}$ afforded target pyridines 47 in lower yield, presumably due to partial hydrolysis of the unstable intermediate cycloadduct. The reaction was applied towards highly functionalized furopyridine derivatives possessing MEK kinase inhibitory activity. ${ }^{46}$ 
Table 2. Survey of Lewis acids for the synthesis of 3-hydroxypyridines<smiles>CCOc1oc(C)nc1Br</smiles>

42<smiles>COC(=O)/C=C\C(C)OC</smiles>

43

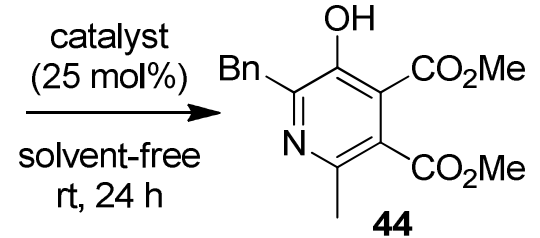

\begin{tabular}{ccc}
\hline Entry & Catalyst & Yield $^{\mathbf{a}}$ \\
\hline 1 & None & 0 \\
2 & $\mathrm{Sc}(\mathrm{OTf})_{3}$ & 10 \\
3 & $\mathrm{Eu}(\mathrm{OTf})_{3}$ & 31 \\
4 & $\mathrm{Yb}(\mathrm{OTf})_{3}$ & 38 \\
5 & $\mathrm{La}(\mathrm{OTf})_{3}$ & 57 \\
6 & $\mathrm{Sm}(\mathrm{OTf})_{3}$ & 58 \\
7 & $\mathrm{Nd}(\mathrm{OTf})_{3}$ & $59(72)^{\mathrm{b}}$ \\
8 & $\mathrm{TfOH}$ & 0 \\
9 & $\mathrm{Hf}(\mathrm{OTf})_{4} \cdot \mathrm{H}_{2} \mathrm{O}$ & $<5$ \\
10 & $\mathrm{Cu}(\mathrm{OTf})_{2}$ & 0 \\
\hline
\end{tabular}

${ }^{a}$ Yield determined by $1 \mathrm{H}-\mathrm{NMR}$ of the crude reaction mixture relative to $\mathbf{4 2}^{{ }^{b}}$ Isolated yield using 40 $\operatorname{mol} \%$ of $\mathrm{Nd}(\mathrm{OTf})_{3}$.

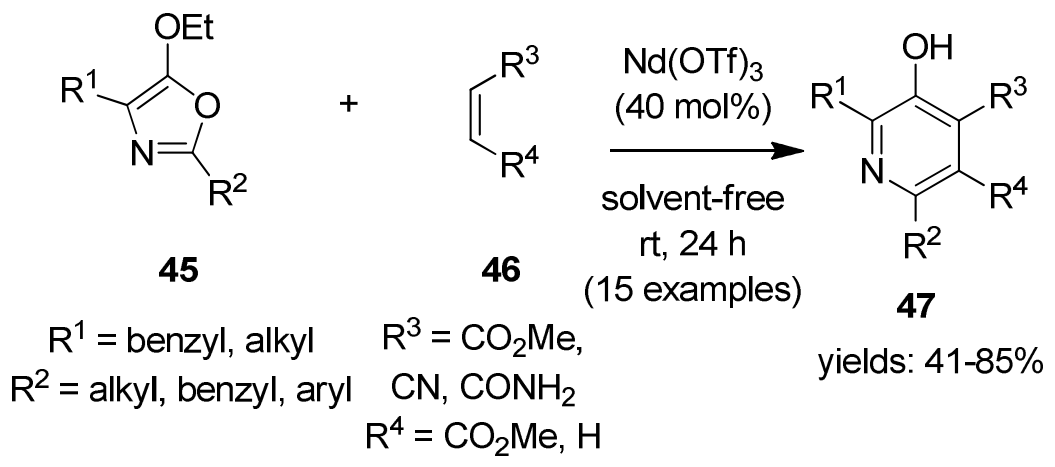

Scheme 11. Scope of Nd(III)-catalyzed Kondrat'eva reaction.

A mild and efficient approach to $c i s$-fused tetrahydrochromeno[4,3- $b$ ]quinolines via intramolecular Povarov reaction of aromatic amines 48 with 7-O-prenyl-8-formyl chromenones 49 was reported. ${ }^{47}$ Among the catalysts surveyed $\left(\mathrm{ZnCl}_{2}, \mathrm{NbCl}_{5}, \mathrm{FeCl}_{3}\right.$, etc.), the best results in terms of reaction times, yields, and diastereoselectivity were obtained with $\mathrm{Yb}(\mathrm{OTf})_{3}$ in refluxing $\mathrm{MeCN}$ (Scheme 12). A number of new cis-fused tetrahydrochromeno[4,3-b]quinolines $\mathbf{5 0}$ 
demonstrated significant antiproliferative effects in breast cancer cell lines comparable to Tamoxifen.

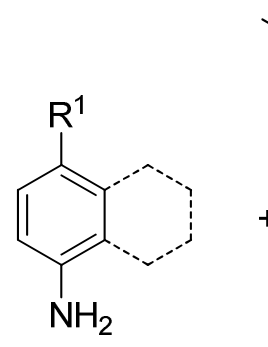

48<smiles>CC(C)=CCOc1ccc2c(=O)c(C)c(C)oc2c1C=O</smiles>

49

$\mathrm{R}^{1}=\mathrm{H}, \mathrm{Me}, \mathrm{MeO}, \mathrm{Br}$, etc.

(11 examples)

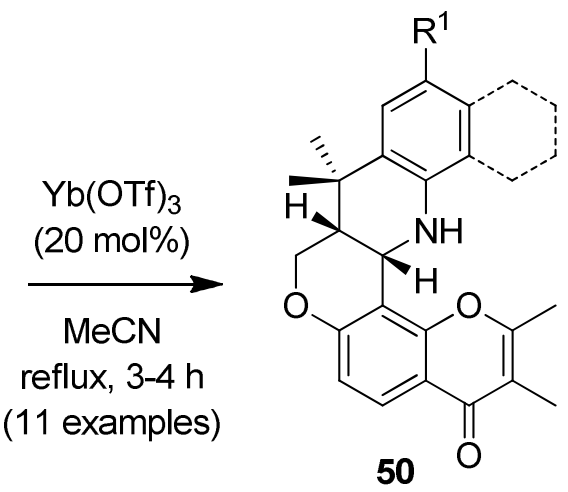

yields: $85-95 \%$

Scheme 12. $\mathrm{Yb}(\mathrm{III})$-catalyzed synthesis of tetrahydrochromeno[4,3-b]quinolines analogs.

A catalytic enantioselective aza-Diels-Alder reaction of Brassard's diene $\mathbf{5 1}$ with aldimines 52 was reported. ${ }^{48}$ In contrast with Danishefsky's diene, a double substitution in Brassard's diene terminus hindered the enantioselectivity of the hetero-Diels-Alder reaction under standard conditions. Gratifyingly, a complex of previously mentioned $N, N^{\prime}$-dioxide 32 with $\mathrm{Yb}(\mathrm{OTf})_{3}$ afforded the corresponding $\alpha, \beta$-unsaturated $\gamma$-lactone derivatives 54 in a two-step process via a Mannich product 53 with moderate to good yields and good enantioselectivities (Scheme 13).

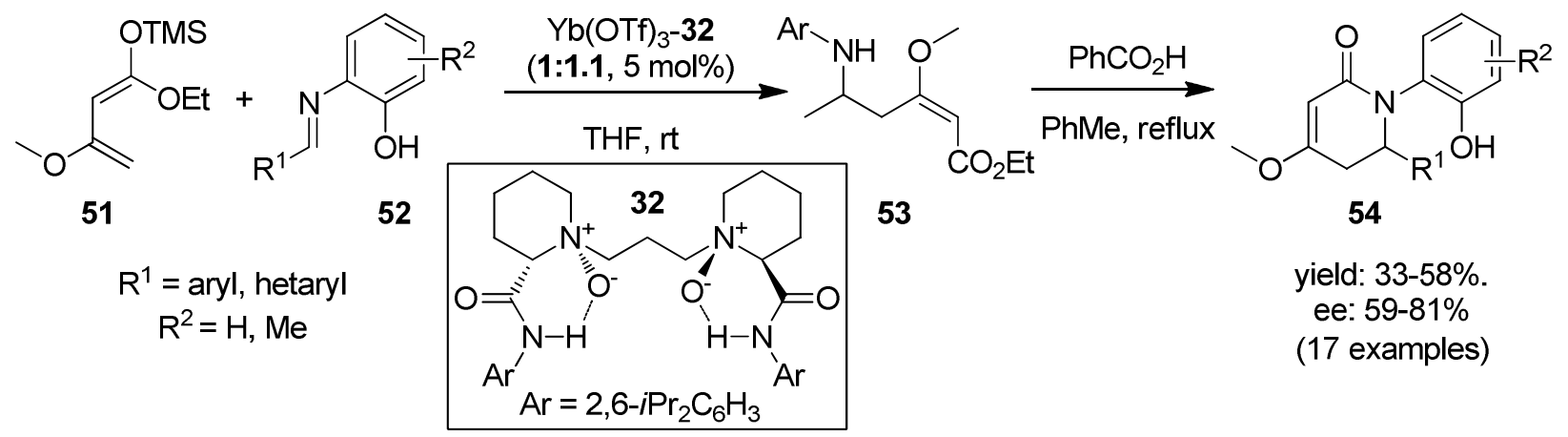

Scheme 13. Enantioselective Yb(III)-catalyzed aza-Diels-Alder reaction with Brassard's diene.

A structurally related $L$-ramipril-acid-derived $N, N^{\prime}$-dioxide $\mathbf{5 8}$ ligand was successfully employed in a $\mathrm{Sc}(\mathrm{OTf})_{3}$-catalyzed three-component inverse electron-demand aza-Diels-Alder reaction (IEDDA) to yield ring-fused tetrahydroquinolines 59 with high enantio- and diastereoselectivities. ${ }^{49}$ Feng et al. demonstrated that $\mathrm{Sc}(\mathrm{OTf})_{3}$ was a superior co-catalyst for the reaction, and the reaction tolerated a wide range of electronically and sterically diverse aldehydes 55 (Scheme 14). The reaction was successfully performed on gram scale without any loss of 
selectivity, and the obtained material was structurally elaborated further to tetrahydroquinoline derivatives of potential medicinal importance.

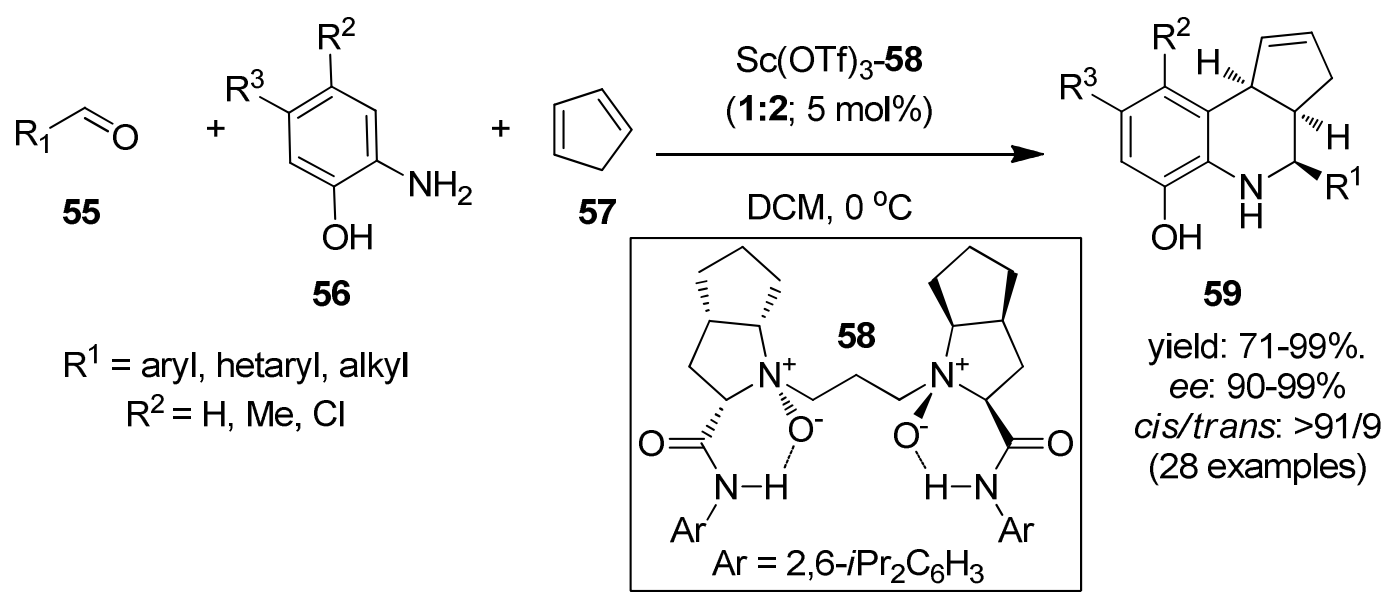

Scheme 14. Asymmetric $\mathrm{Sc}(\mathrm{OTf})_{3}$-catalyzed IEDDA reaction.

The fact that $\mathrm{Yb}(\mathrm{OTf})_{3}$ efficiently activates Schiff bases for the hetero-Diels-Alder reaction has motivated Wang et al. to study a three-component reaction of aromatic aldehydes 60, naphthalen-2-amine 61, and but-2-ynedioate $\mathbf{6 2}$ to yield 3-arylbenzo[f]quinoline-1,2dicarboxylates 63. ${ }^{50}$ Indeed, a broad range of aromatic aldehydes, bearing both electronaccepting and electron-donating groups, reacted smoothly to produce the desired products (Scheme 15).<smiles>[R]c1ccc(C=O)cc1[NH2+]</smiles>

60<smiles>Nc1ccc2ccccc2c1</smiles>

61

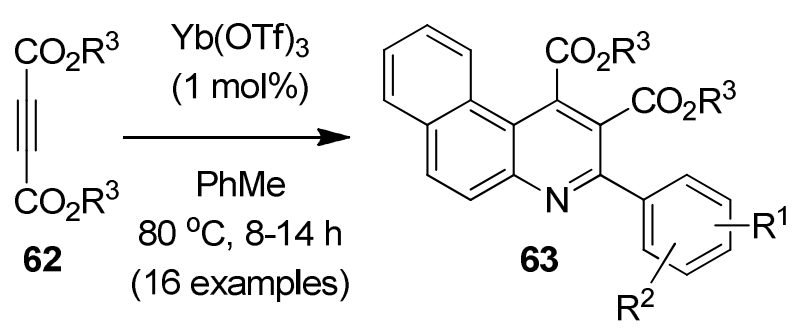

yields: $77-92 \%$

Scheme 15. $\mathrm{Sc}(\mathrm{OTf})_{3}$-catalyzed three-component reaction.

Cis-4,5-substituted pyrrolidinones bearing aromatic and heteroaromatic groups are considered structures of medicinal importance. ${ }^{51}$ A novel, operationally simple, three-component assembly of these privileged structures, based on readily available furancarbaldehydes 64, anilines 65, and cyclopropanated N-Boc pyrrole 66, was reported in 2012 (Scheme 16). ${ }^{52}$ Among a number of Lewis acids screened, $\mathrm{Sc}(\mathrm{OTf})_{3}$ was found to be the optimal catalyst for the transformation. A plausible mechanism of this reaction, involving $\mathrm{Sc}(\mathrm{OTf})_{3}$-mediated 
cyclopropane ring opening, furan migration, and final rearomatization leading to a range of

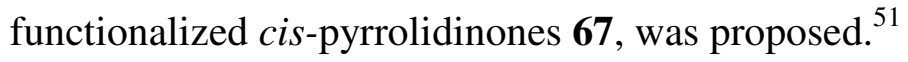

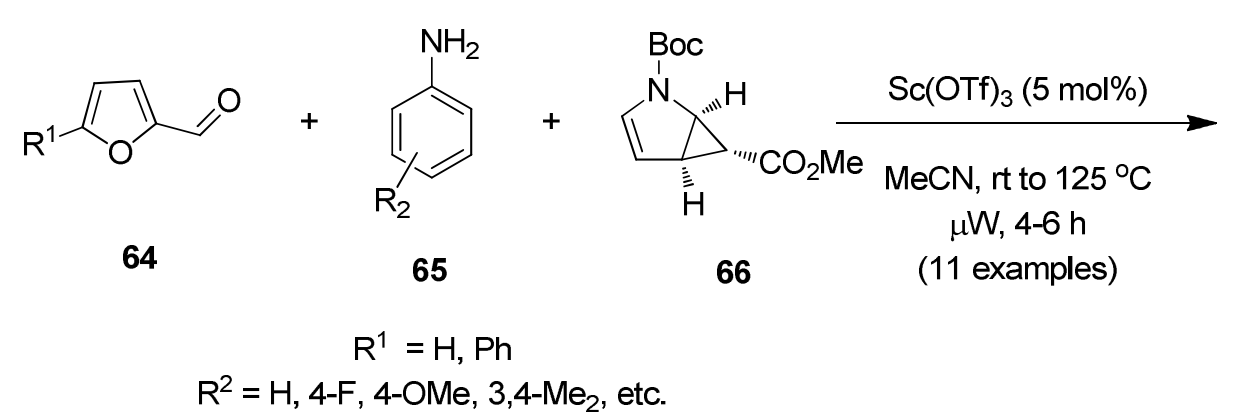

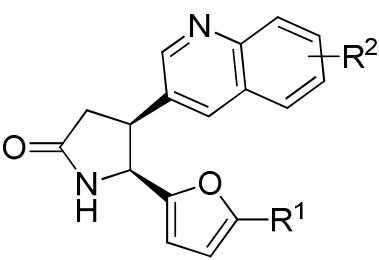

67

cis- only

Scheme 16. Three-component assembly of cis-4,5-substituted pyrrolidinones 67.

\section{3 [3+2] Cycloadditions and related processes}

1,3-Dipolar cycloaddition is one of the most important reaction classes in synthetic heterocyclic chemistry, and it has found broad application as an efficient, regio- and stereocontrolled, and high-yielding method for the synthesis of diverse heterocyclic systems of considerable complexity. ${ }^{17,53-55}$ Discussed below is a selection of compelling examples of $\mathrm{M}(\mathrm{OTf})_{3}$-catalyzed $[3+2]$ cycloadditions and related processes published in the last five years.

The generation of reactive carbonyl yildes via mild $\mathrm{Yb}(\mathrm{OTf})_{3}$-catalyzed $\mathrm{C}-\mathrm{C}$ heterolysis of the respective oxiranes 68 was disclosed by Zhang et al. ${ }^{56}$ Among Lewis acids tested to effect the transformation, conventional Lewis acids such as $\mathrm{Sn}(\mathrm{OTf})_{2}, \mathrm{Bi}(\mathrm{OTf})_{3}, \mathrm{Fe}(\mathrm{OTf})_{3}$, and $\mathrm{Mg}(\mathrm{OTf})_{2}$ resulted in either low efficiency or no catalytic activity. On the other hand, $\mathrm{Sc}(\mathrm{OTf})_{3}$, $\mathrm{Y}(\mathrm{OTf})_{3}$ and $\mathrm{Yb}(\mathrm{OTf})_{3}$ effected smooth reaction. The latter catalyst was marginally better for carbonyl ylide generation, and subsequent [3+2] cycloaddition of the generated carbonyl ylides with a range of aldehydes afforded synthetically useful cis-1,3-disubstituted 1,3-dioxolanes 70 in excellent yields (Scheme 17). A mechanism for the aforementioned transformation, featuring direct oxiranes $68 \mathrm{C}$-C bond heterolysis, followed by a reaction of $\mathrm{Yb}$-coordinated ylide with aldehydes 69 and final ring closure, was postulated.

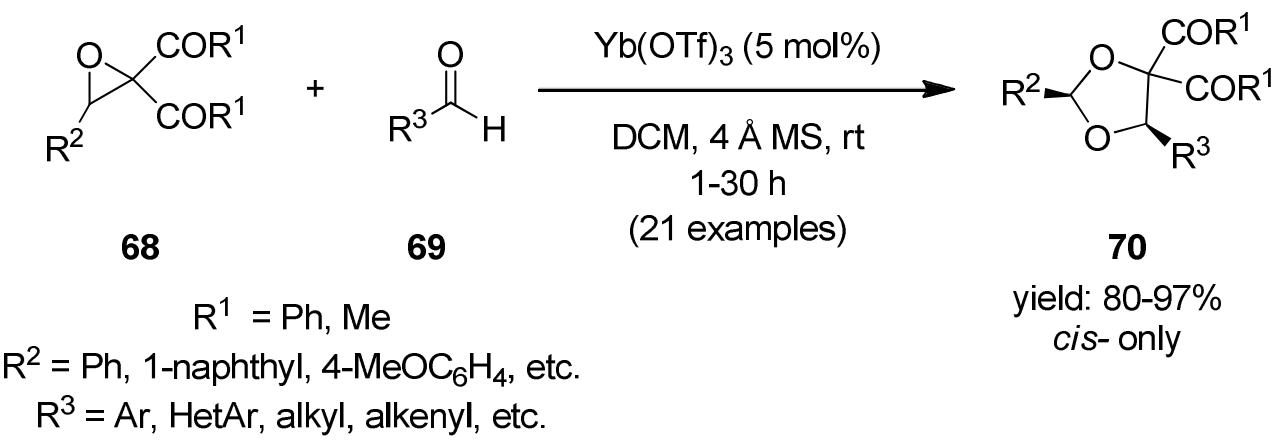

Scheme 17. 1,3-Dipolar cycloaddition catalyzed by $\mathrm{Yb}(\mathrm{OTf})_{3}$. 
In a subsequent publication, the same research group disclosed a highly regioselective $\mathrm{Sc}(\mathrm{OTf})_{3}$-catalyzed 1,3-dipolar cycloaddition of alkynes with azomethine ylides providing highly substituted 3-pyrrolines 73 (Scheme 18). ${ }^{57}$ Analogous to a previous transformation, Ln(OTf) 3 was a key reagent to effect facile generation of azomethine ylides from N-Tos aziridines 71 via C-C heterolysis. Preliminary investigations revealed that moderate enantioselectivity can be achieved with a PyBox ligand.

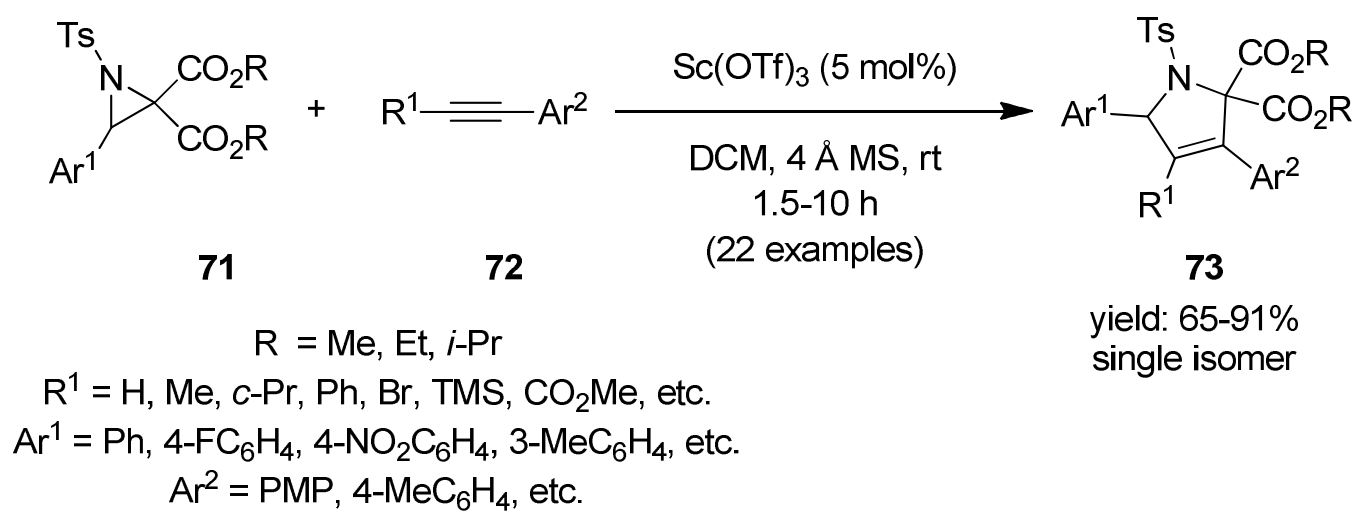

Scheme 18. Preparation of 3-pyrrolines 73 via [3+2] cycloaddition.

An interesting tandem cyclization/[3+3] cycloaddition of 2-alkynylbenzaldoximes 74 with dimethyl cyclopropane-1,1-carboxylates 75, co-catalyzed by AgOTf and $\mathrm{Yb}(\mathrm{OTf})_{3}$, was reported by $\mathrm{Wu}$ and co-workers (Scheme 19). ${ }^{58}$ This dually-catalyzed procedure represents a facile and useful protocol to prepare tetrahydro-1,2-oxazine fused 1,2-dihydroisoquinolines 76, which may serve as building blocks for pharmaceutically active compounds.

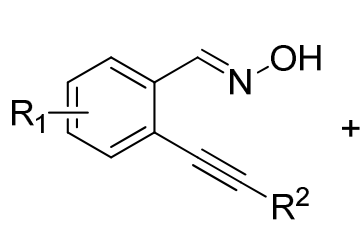

74 $\mathrm{R}^{1}=\mathrm{F}, \mathrm{MeO}$, etc. $\mathrm{R}^{2}=\mathrm{Ph}, \mathrm{PMP}, n-\mathrm{Bu}, c-\mathrm{Pr}$, etc. $\mathrm{R}^{3}=\mathrm{H}, \mathrm{Ph}$

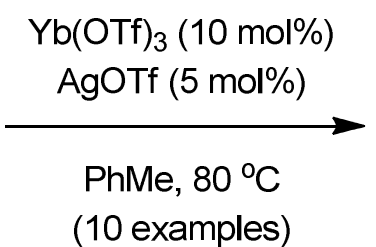

(10 examples)

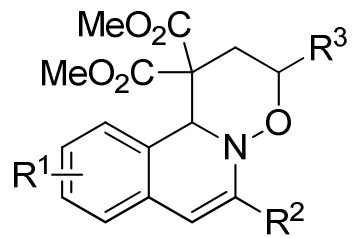

76

yield: $65-91 \%$ single isomer

Scheme 19. Tandem cyclization/[3+3] cycloaddition.

A variety of structurally diverse tetrahydro-1,2-oxazines 79 can be prepared by treatment of methylenecyclopropane-1,1-diesters (MCP) 77 with $\mathrm{C}, \mathrm{N}$-disubstituted nitrones $\mathbf{7 8}$ in the presence of $\mathrm{Yb}(\mathrm{OTf})_{3}$ (Scheme 20). ${ }^{59} \mathrm{Sc}(\mathrm{OTf})_{3}$ and $\mathrm{Mg}\left(\mathrm{ClO}_{4}\right)_{2} \cdot 6 \mathrm{H}_{2} \mathrm{O}$ also promoted the reaction, 
albeit with lower efficiency. While aryl-substituted nitrones 78 converted to tetrahydro-1,2oxazines 79 smoothly, it should be mentioned that reactions of $\mathrm{C}, \mathrm{N}$-dialkyl nitrones did not give positive results, presumably due to the intrinsic instability of such nitrones to Lewis acids. A three-component, one-pot adaptation of this distal [3+3] cycloaddition, consisting of in situ generation of $C, N$-diarylnitrone reagents, was also developed.

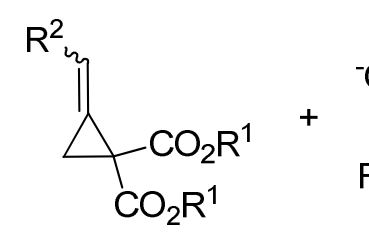

77

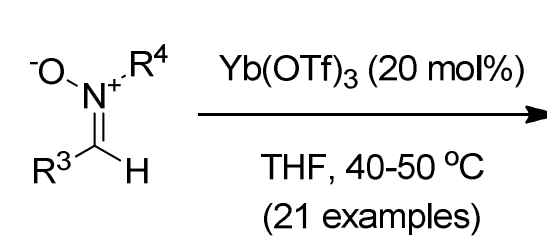

78

$$
\begin{gathered}
R^{1}=\text { Me, Et; } R^{2}=\text { Ar, Alk } \\
R^{3}=\text { Ph, Ar, HetAr; } R^{4}=\text { Ar, Me }
\end{gathered}
$$

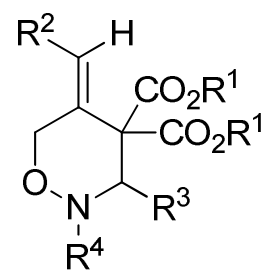

79

yield: $51-98 \%$

Z-isomer only

Scheme 20. Synthesis of 1,2-oxazinanes 79.

Wang et al. developed an intramolecular [3+2] cross-cycloaddition of donor-acceptor cyclopropanes with aldehydes or ketones for the construction of bridged oxa-[n.2.1.] skeletons 81 (Scheme 21). ${ }^{60}$ The reaction is promoted by $\mathrm{Sc}(\mathrm{OTf})_{3}$, proceeds in a stereoselective manner and can also be applied successfully towards imines to yield aza-[n.2.1.] systems. The reported methodology was showcased in the course of a platensimycin formal synthesis and a $( \pm)$ bruguierol A total synthesis. ${ }^{61,62}$ The same $\mathrm{Sc}(\mathrm{OTf})_{3}$ methodology subsequently was utilized to expediently construct bridged [n.2.1] carbocyclic systems via a novel intramolecular [3+2] process involving alkenes and donor-acceptor cyclopropanes. ${ }^{63}$ The strategy was successfully applied to the total synthesis of tetracyclic diterpenoids phyllocladanol and phyllocladene.

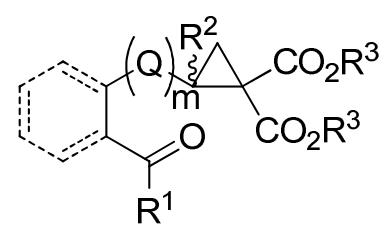

80

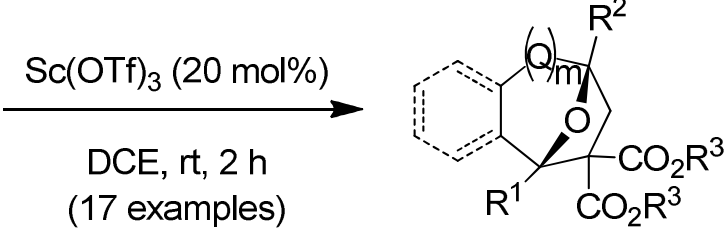

81

$$
\begin{gathered}
R^{1}=\mathrm{H}, \mathrm{Me} \text {, vinyl, etc.; } \mathrm{R}^{2}=\mathrm{H}, \mathrm{Me} \\
\quad \mathrm{R}^{3}=\mathrm{Me}, \mathrm{Et} \\
\mathrm{Q}=\mathrm{CH}_{2}, \mathrm{O}, \mathrm{S} ; \mathrm{m}=0,1,2
\end{gathered}
$$

yield: $27-91 \%$

Scheme 21. Construction of oxa-[n.2.1] skeletons 81.

A logical extension of the analogous $\mathrm{M}(\mathrm{OTf})_{3}$-catalyzed cycloaddition reactions to homologous donor-acceptor cyclobutanes was reported in 2009-2011 by Johnson ${ }^{64}$ and 
Pagenkopf. ${ }^{65,66}$ For instance, structurally unique 2,3,4,6,7-substituted oxazepines 84 can be prepared from a wide selection of nitrones $\mathbf{8 2}$ and activated donor-acceptor cyclobutane $\mathbf{8 3}$ (Scheme 22). ${ }^{67}$ This formal [4+3] cycloaddition is catalyzed by $\mathrm{Yb}(\mathrm{OTf})_{3}$, and, in most cases, initially affords a diastereomeric mixture, which equilibrates to a single diastereomer. Nitrones 82 bearing both electron-rich and electron-deficient $\mathrm{N}$-aryl groups were found to be viable cycloaddition partners.

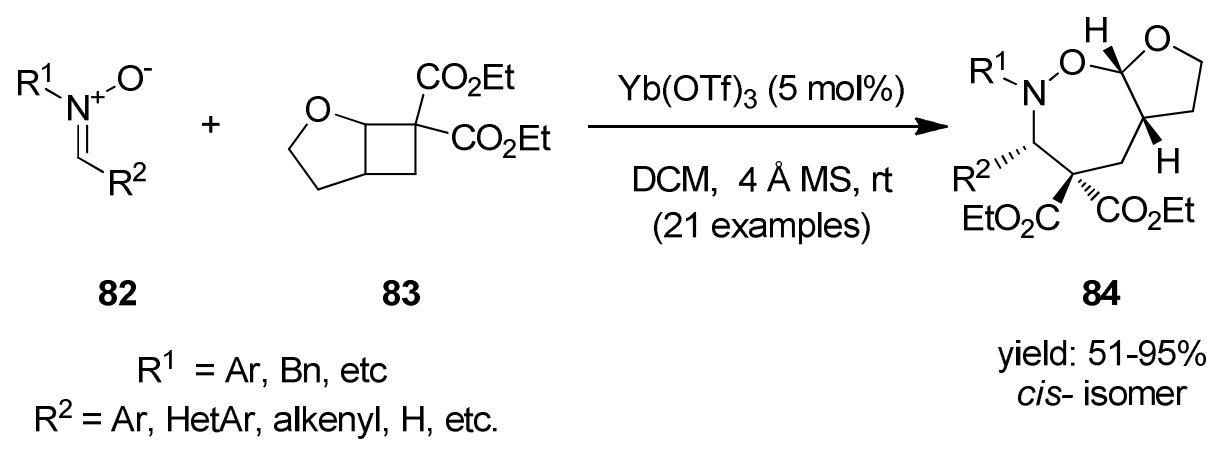

Scheme 22. Formal [4+3] cycloaddition of donor-acceptor cyclobutane $\mathbf{8 3}$.

\section{4 [1,5]-H Shift/ring closure reactions}

In the last decade $\mathrm{sp}^{3}-\mathrm{C}-\mathrm{H}$ bond functionalization via an internal redox process, which involves a [1,5]-hydride shift from the activated carbon atom, followed by cyclization, has attracted much attention. Specifically, $\mathrm{Sc}(\mathrm{OTf})_{3}$ was used to achieve [1,5]-H shift mediated $\mathrm{C}-\mathrm{H}$ bond functionalization to furnish tetraline derivatives $\mathbf{8 6}$ (Scheme 23) ${ }^{68,69}$ It should be noted that sterically hindered substrates 85 (e.g. $\mathrm{R}^{1}=$ Mes) showed considerably lower reactivity, and required higher $\mathrm{Sc}(\mathrm{OTf})_{3}$ catalyst loadings. Remarkably, the reaction is operational for purely aliphatic substrates $\mathbf{8 5}$, and $\gamma$-alkyl side chain substrates provided unexpected indane derivatives via $[1,6]-H$ process. ${ }^{68}$<smiles>[R]C([R])Cc1ccccc1C=C1C(=O)N(C)C(=O)N(C)C1=O</smiles>

85

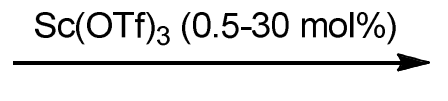

1,2-DCE, reflux (13 examples)

86

yield: $25-98 \%$

$\mathrm{R}^{1}, \mathrm{R}^{2}=\mathrm{Me}, \mathrm{Et}$, alkyl

$\mathrm{R}^{1}=\mathrm{Ar}, \mathrm{R}^{2}=\mathrm{H}$

Scheme 23. Sc(OTf)3-catalyzed hydride shift/cyclization. 
An analogous $\mathrm{Sc}(\mathrm{OTf})_{3}$-mediated hydride-transfer cyclization of ortho-vinylaryl alkyl ethers 87 was reported by Sames and co-workers (Scheme 24). ${ }^{70}$ Other Lewis acids including $\mathrm{BF}_{3} \cdot \mathrm{Et}_{2} \mathrm{O}, \mathrm{PtCl}_{4}, \mathrm{TiCl}_{4}$, and $\mathrm{Cu}(\mathrm{OTf})_{2}$ were much less efficient, resulting in no conversion or low reaction rates. It should be noted that other members of the lanthanide family, $\mathrm{Yb}(\mathrm{OTf})_{3}$ and $\mathrm{Gd}(\mathrm{OTf})_{3}$, were less efficient catalysts as well, underscoring the unique catalytic activity of scandium triflate for this transformation.

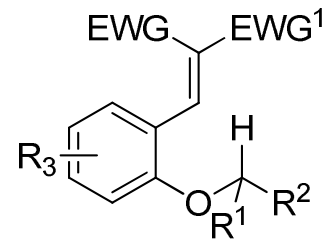

87

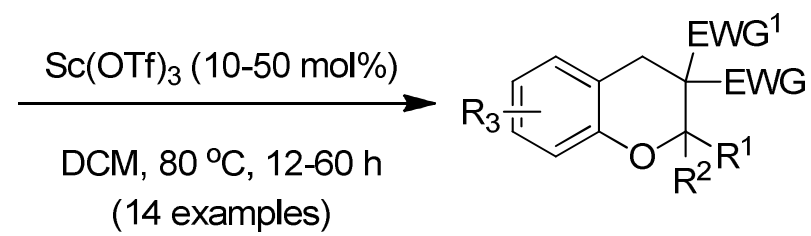

88

$\mathrm{R}^{1}, \mathrm{R}^{2}=\mathrm{Me}$, -cycloalkyl-, $\mathrm{Ph}$, Allyl yield: $32-95 \%$

EWG, $\mathrm{EWG}^{1}=\mathrm{CO}_{2} \mathrm{Me}, \mathrm{Ac}, \mathrm{SO}_{2} \mathrm{Ph}$

$\mathrm{R}^{3}=\mathrm{OMe}, \mathrm{Br}, \mathrm{Et}_{2} \mathrm{~N}$, etc.

Scheme 24. Preparation of dihydrobenzopyrans 88.

In an effort to develop intramolecular redox $\mathrm{C}-\mathrm{H}$ functionalization to access tetrahydroquinolines, Seidel and his research group studied [1,5]-hydride shift/ring closure of $N$-arylamines 89 under various reaction conditions (Table 3). ${ }^{71}$ Among the Lewis acids tested, Sc(OTf) ${ }_{3}$ and $\mathrm{La}(\mathrm{OTf})_{3}$ served as effective reaction promoters. Further, gadolinium triflate showed remarkable rate acceleration in the series of tested catalysts (entries 13 and 16) and was ultimately selected as a catalyst of choice for the reaction.

Table 3. Screening of Lewis acid catalysts ${ }^{a}$<smiles>COC(=O)C(=Cc1ccccc1N1CCCC1)C(=O)OC</smiles>

89

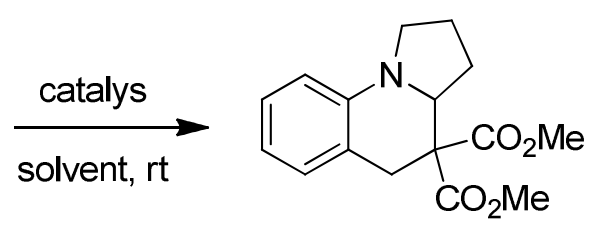

90

\begin{tabular}{cccccc}
\hline Entry & Catalyst & $\begin{array}{c}\text { Mol } \\
\%\end{array}$ & Solvent & Time & $\begin{array}{c}\text { Yield } \\
(\%)\end{array}$ \\
\hline 1 & $\operatorname{Mg}(\mathrm{OTf})_{2}$ & 20 & DCM & $24 \mathrm{~h}$ & $20^{\mathrm{b}}$ \\
2 & $\mathrm{Mg}\left(\mathrm{ClO}_{4}\right)_{2}$ & 20 & DCM & $20 \mathrm{~h}$ & 83 \\
3 & $\mathrm{Mg}\left(\mathrm{ClO}_{4}\right)_{2} \cdot 6 \mathrm{H}_{2} \mathrm{O}$ & 20 & DCM & $24 \mathrm{~h}$ & Trace \\
4 & $\mathrm{InCl}_{3}$ & 20 & DCM & $24 \mathrm{~h}$ & $66^{\mathrm{b}}$ \\
5 & $\mathrm{Zn}(\mathrm{OTf}) 2$ & 20 & DCM & $24 \mathrm{~h}$ & $72 \mathrm{~b}$ \\
\hline
\end{tabular}


Table 3. Continued

\begin{tabular}{cccccc}
\hline Entry & Catalyst & $\begin{array}{c}\text { Mol } \\
\%\end{array}$ & Solvent & Time & $\begin{array}{c}\text { Yield } \\
(\%)\end{array}$ \\
\hline 6 & $\mathrm{Cu}(\mathrm{OTf})_{2}$ & 20 & $\mathrm{DCM}$ & $24 \mathrm{~h}$ & 55 \\
7 & $\mathrm{Ni}\left(\mathrm{ClO}_{4}\right)_{2} \cdot 6 \mathrm{H}_{2} \mathrm{O}$ & 20 & $\mathrm{DCM}$ & $24 \mathrm{~h}$ & $28^{\mathrm{b}}$ \\
8 & $\mathrm{FeCl}_{3} \cdot 6 \mathrm{H}_{2} \mathrm{O}$ & 20 & $\mathrm{DCM}$ & $24 \mathrm{~h}$ & Trace \\
9 & $\mathrm{Yb}(\mathrm{OTf})_{3}$ & 20 & $\mathrm{DCM}$ & $2.5 \mathrm{~h}$ & 84 \\
10 & $\mathrm{Sc}(\mathrm{OTf})_{3}$ & 20 & $\mathrm{DCM}$ & $30 \mathrm{~min}$ & 86 \\
11 & $\mathrm{Sc}(\mathrm{OTf})_{3}$ & 20 & $\mathrm{MeCN}$ & $1 \mathrm{~h}$ & 93 \\
12 & $\mathrm{Sc}(\mathrm{OTf})_{3}$ & 10 & $\mathrm{MeCN}$ & $4 \mathrm{~h}$ & 93 \\
13 & $\mathrm{Sc}(\mathrm{OTf})_{3}$ & 5 & $\mathrm{MeCN}$ & $22 \mathrm{~h}$ & 83 \\
14 & $\mathrm{La}(\mathrm{OTf})_{3}$ & 10 & $\mathrm{MeCN}$ & $45 \mathrm{~min}$ & 86 \\
15 & $\mathrm{Gd}(\mathrm{OTf})_{3}$ & 10 & $\mathrm{MeCN}$ & $15 \mathrm{~min}$ & 93 \\
16 & $\mathrm{Gd}(\mathrm{OTf})_{3}$ & 5 & $\mathrm{MeCN}$ & $15 \mathrm{~min}$ & 90 \\
17 & $\mathrm{Gd}(\mathrm{OTf})_{3}$ & 5 & $\mathrm{DCM}$ & $50 \mathrm{~min}$ & 75 \\
\hline
\end{tabular}

Performed on $0.25 \mathrm{mmol}$ scale in a given solvent $(0.1 \mathrm{M})$ to full conversion by TLC analysis.

${ }^{\mathrm{b}}$ Determined by ${ }^{1} \mathrm{H}-\mathrm{NMR}$.

The aforementioned cyclization protocol showed wide reaction scope with respect to both the amine donor moiety and the acceptor residue, allowing rapid access to complex tetrahydroquinolines 92 (Scheme 25). ${ }^{71}$ The transformation is rather general, with the exception of dinitrile derivatives $91\left(\mathrm{Z}, \mathrm{Z}^{\prime}=\mathrm{CN}\right)$, which could be explained by the limited propensity of $\mathrm{CN}$ groups to engage in chelating interactions. Preliminary results indicated that the reaction could be performed in an enantioselective fashion utilizing a Box ligand.<smiles>[Z]C([Z])=Cc1ccccc1N(C([R])C)C([R])C1CC1</smiles>

91

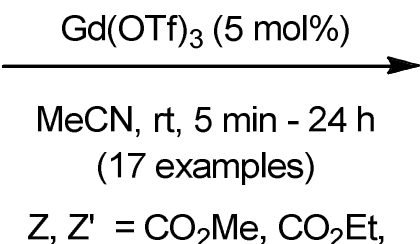
$\mathrm{CO}_{2} \mathrm{tBu}, \mathrm{CO}_{2} \mathrm{Bn}, \mathrm{Ac}, \mathrm{Bz}$ $\mathrm{R}=\mathrm{H}, \mathrm{Me}$ $\mathrm{R}^{\prime}=\mathrm{Ph}$, etc. $n=1,2,3,4$

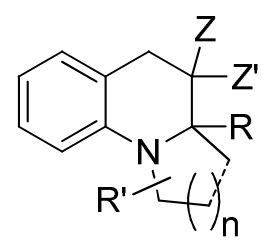

92 yield: $57-94 \%$

Scheme 25. Efficient Gd(III)-catalyzed cyclization.

\subsection{Radical cyclizations}

In the past 20 years, free radical reactions have received much attention, and a wide variety of synthetic methods has been developed in the field. ${ }^{72}$ The use of Lewis acids in radical reactions 
to control reactivity as well as regio- and stereoselectivity was likewise a subject of numerous research publications in the past two decades. ${ }^{73}$ Owing to their oxophilic character, water tolerability and pronounced Lewis acidic properties, lanthanide triflates were also successfully employed in a number of free radical processes. ${ }^{10-15}$

Yang and co-workers have disclosed $\mathrm{Yb}(\mathrm{OTf})_{3}$-promoted 5-/6-exo-trig radical cyclization of $\alpha$-phenylseleno amido esters 93 under UV irradiation to give rise to mono- and bicyclic nitogen heterocycles 94 (Scheme 26). ${ }^{74}$ It was suggested that $\mathrm{Yb}(\mathrm{OTf})_{3}$ played a two-fold role in promoting the radical process: increased electrophilicity of the $\alpha$-radical intermediate via 1,3 dicarbonyl moiety chelation and accelerated $\mathrm{PhSe}$ group transfer.

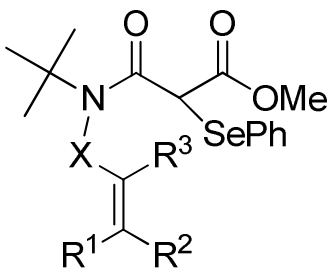

93

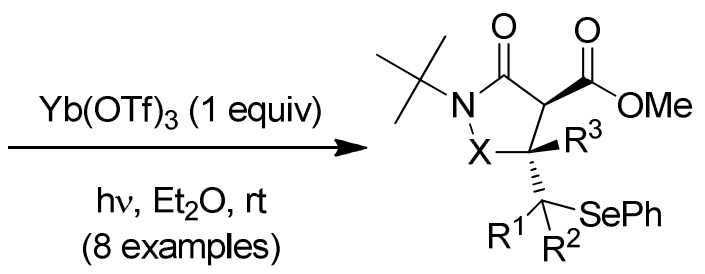

94

$R^{1}, R^{2}, R^{3}=H, M e ; X=\mathrm{CH}_{2},\left(\mathrm{CH}_{2}\right)_{2}$

yield: $81-95 \%$

trans- major

$$
\mathrm{R}^{2}, \mathrm{R}^{3}=\mathrm{H} ; \mathrm{X}=-\left(\mathrm{CH}_{2}\right)_{3^{-}},-\left(\mathrm{CH}_{2}\right)_{4^{-}}
$$

Scheme 26. $\mathrm{Yb}(\mathrm{OTf})_{3}$-promoted radical cyclization.

In 2011, Yoon et al. reported a photocatalytic intramolecular cyclization of alkenyl cyclopropyl ketones 95, which is accomplished using a system comprised of $\mathrm{La}(\mathrm{OTf})_{3}$, $\mathrm{Ru}(\mathrm{bpy})_{3}{ }^{2+}$ and TMEDA (Scheme 27). ${ }^{75}$ The cyclization involves generation of a distonic radical anion, which upon sequential radical cyclization, and loss of electrons produces cyclopentanecontaining frameworks 96 in a rapid diastereoselective fashion. $\mathrm{La}(\mathrm{OTf})_{3}$ was critical to the efficiency of the reaction and was presumably activating substrate 95 towards one-electron reduction via chelation.

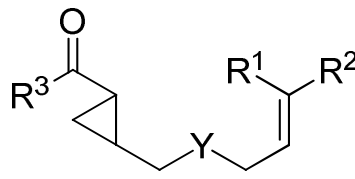

95

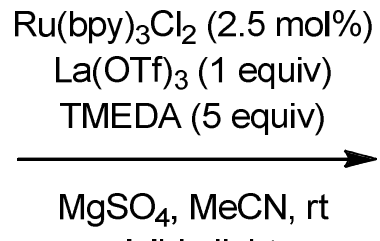

visible light

(16 examples) $\mathrm{R}^{1}=\mathrm{H}, \mathrm{Me}, \mathrm{Et}$

$$
\begin{gathered}
\mathrm{R}^{2}=\mathrm{CO}_{2} \mathrm{Et}, \mathrm{CO}_{2} t-\mathrm{Bu}, \mathrm{COSEt}, \mathrm{Ph} \text {, etc. } \\
\mathrm{R}^{3}=\mathrm{Ph}, \mathrm{PMP}, 4-\mathrm{CIC}_{6} \mathrm{H}_{4} \\
\mathrm{Y}=\mathrm{CH}_{2},\left(\mathrm{CH}_{2}\right)_{2}, \mathrm{O} \text {, etc. }
\end{gathered}
$$

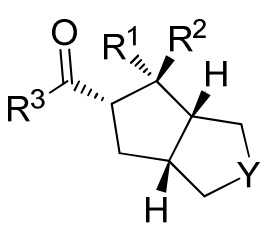

96

yield: $57-83 \%$ up to $10: 1 \mathrm{dr}$

Scheme 27. Scope of photocatalytic intramolecular cyclization. 


\subsection{Other cyclization reactions}

In addition to the reaction classes discussed above, rare earth metal triflates efficiently catalyze a number of other cyclization processes. ${ }^{10-15}$ A selection of recent examples of these useful organic transformations, including Prins-type cyclization, three-component cyclization, and heterocycle syntheses, will be highlighted in this section.

$\mathrm{Sc}(\mathrm{OTf})_{3}$ can be successfully used as a promoter for intramolecular condensations of ynol ether-acetals. Specifically, Minehan and his group have disclosed a facile procedure to access 5-, 6- and 7-membered alkoxycycloalkane carboxylates 98 in good to excellent yields under mild reaction conditions (Scheme 28). ${ }^{76}$ The obtained compounds 98 may serve as useful intermediates for natural product synthesis.

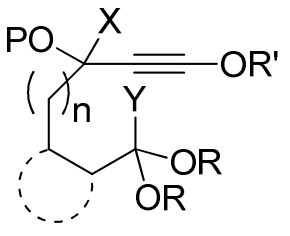

97

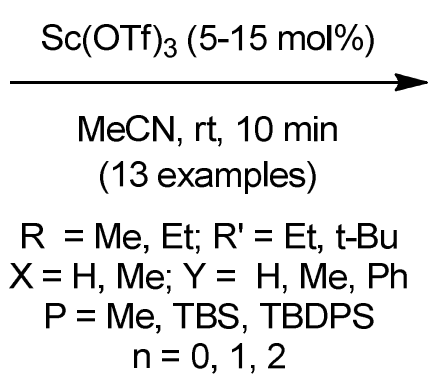

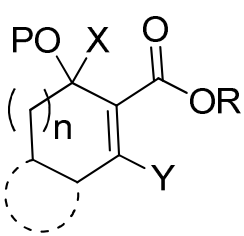

98

yield: $55-92 \%$

Scheme 28. Synthesis of alkoxycycloalkene carboxylates 98 .

In contrast to employing strong acids and harsh reaction conditions for classical Prins cyclization, Subba Reddy and co-workers reported that the intramolecular Prins cyclization was efficiently promoted by $\mathrm{Sc}(\mathrm{OTf})_{3}$ in DCE under mild heating (Scheme 29). ${ }^{77}$ The reaction represents an entirely new approach for synthesizing heterobicycles 101 from aldehydes 99 and bis-homoallyl derivatives $\mathbf{1 0 0}$ in a convenient one-pot operation.

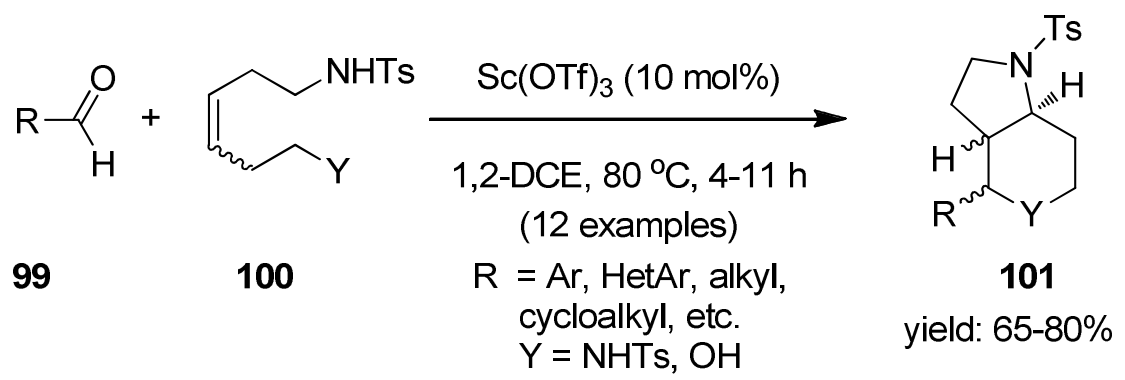

Scheme 29. $\mathrm{Sc}(\mathrm{OTf})_{3}$-catalyzed Prins cyclization.

In a series of publications, Kingsbury and his research group disclosed robust scandium(III) triflate-catalyzed diazoalkane-carbonyl homologations to access functionalized ketones in a rapid fashion and in excellent chemical yields. ${ }^{78-81} \mathrm{Sc}(\mathrm{OTf})_{3}$ appeared to be a highly active catalyst for 
the transformation, with the catalyst loadings as low as $0.5 \mathrm{~mol} \%$ on reaction scales up to 5 mmol. ${ }^{81}$ It deserves mentioning that during the initial attempt to identify suitable catalysts for the transformation, various aluminum- and boron-based Lewis acids were screened unsuccessfully. ${ }^{78}$ The enantioselective version of this protocol was reported, allowing access to medium ring 2aryl cyclic ketones $\mathbf{1 0 4}$ from the respective cyclic ketones $\mathbf{1 0 3}$ in one step in virtually quantitative yields and in up to $96 \%$ ee (Scheme 30$){ }^{80}$

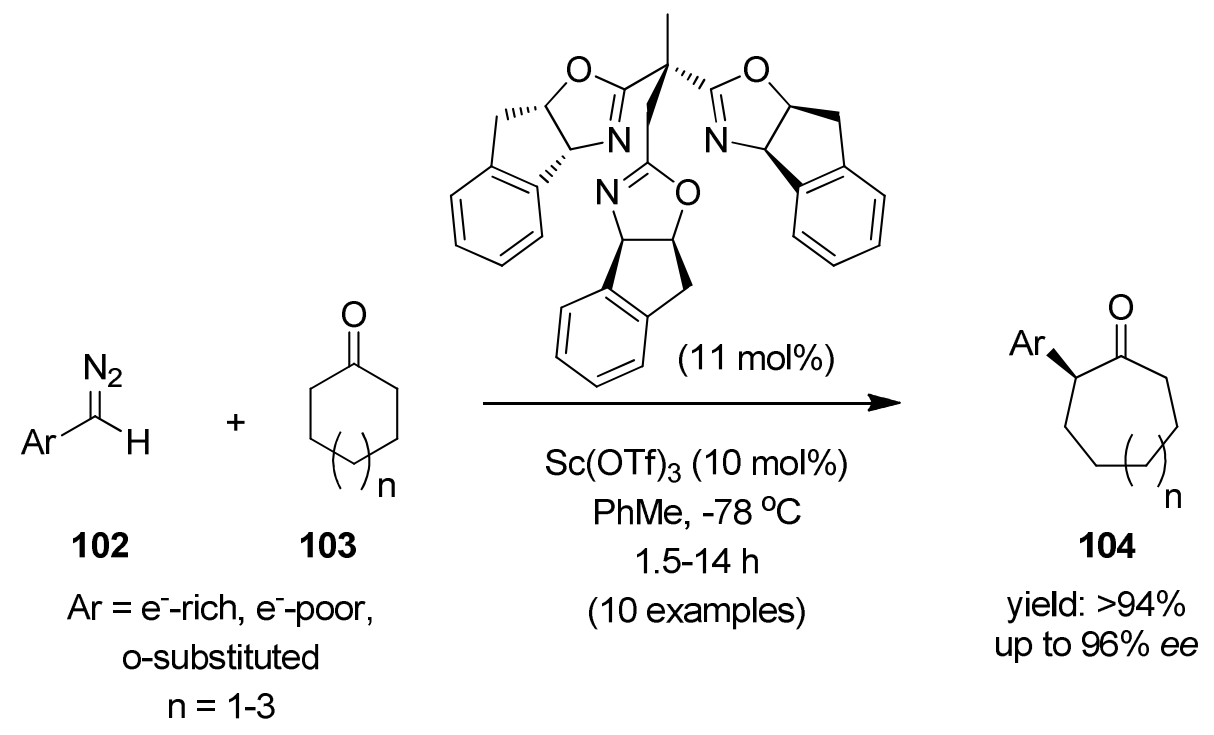

Scheme 30. Enantioselective Sc-catalyzed C-insertion.

Highly substituted 1,4-dihydropyridines $\mathbf{1 0 8}$ and fused bicyclic tetrahydropyridines $\mathbf{1 0 9}$ can be prepared via a novel $\mathrm{Sc}(\mathrm{OTf})_{3}$-catalyzed three-component coupling reaction of arylamines 105, $\beta, \gamma$-unsaturated $\alpha$-ketoesters 106, and 1,3-dicarbonyl compounds 107 (Scheme 31). ${ }^{82}$ Notably, $\mathrm{Cu}(\mathrm{OTf})_{2}$ did not affect the cyclization, and $\mathrm{Zn}(\mathrm{OTf})_{2}, \mathrm{Y}(\mathrm{OTf})_{3}$ and $\mathrm{Yb}(\mathrm{OTf})_{3}$ were less efficient for this reaction, resulting in lower conversion. Prolonged reaction times did not show substantial yield improvement. On the other hand, addition of pyridine-based ligands resulted in increased conversion, presumably due to stabilization of metal complex intermediates. In a preliminary experiment, an asymmetric version of this transformation with $(3 \mathrm{a} R, 8 \mathrm{a} R)$-indanePybox ligand lead to low enantioselectivity and moderate yield. ${ }^{82}$

Application of dysprosium(III)-based Lewis acids in organic synthesis has been a subject of long-standing research interest of Read de Alaniz and his research group. ${ }^{83}$ They reported several inter- and intramolecular variants of the aza-Piancatelli reaction, which were promoted by $\mathrm{Dy}(\mathrm{OTf})_{3}$ and gave rise to a number of complex, highly-functionalized molecular architectures. $^{84-86}$ A 2013 paper from the above-mentioned group disclosed an unprecedented Piancatelli rearrangement involving alcohols as nucleophiles. ${ }^{87}$ The operationally simple reaction is catalyzed by $\mathrm{Dy}(\mathrm{OTf})_{3}$ and proceeds in $\mathrm{PhMe}$ at $80{ }^{\circ} \mathrm{C}$, affording structurally unique transsubstituted spirocyclic ether motif 111 (Scheme 32). It should be noted that the transformation 
effects simultaneous construction of a fully substituted carbon center and a spirocycle, thus achieving exceptional atom economy in a single step.

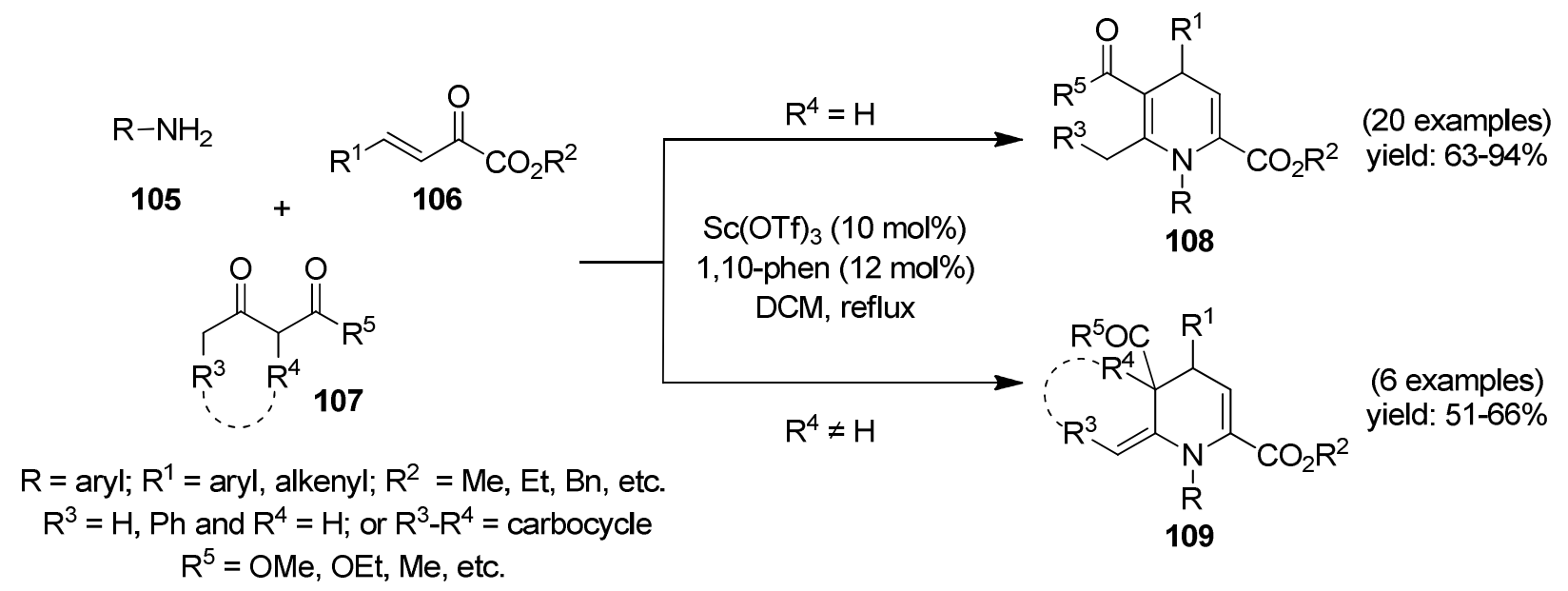

Scheme 31. $\operatorname{Sc}(\mathrm{OTf})_{3}$-catalyzed three-component cyclization.

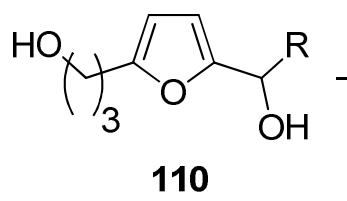

$\mathrm{R}=\mathrm{Ar}, \mathrm{Het} A \mathrm{r}$
$\operatorname{Dy}(\mathrm{OTf})_{3}(5 \mathrm{~mol} \%)$

$\mathrm{PhMe}, 80^{\circ} \mathrm{C}$

(17 examples)<smiles>[R]C1C(=O)C=C[C@]12CCCO2</smiles>

111

yield: $74-91 \%$

trans selective

Scheme 32. Synthesis of spirocycles 111.

During the development of a Lewis acid-catalyzed variant of the Trofimov reaction, ${ }^{88}$ it was shown that among lanthanide(III) salts screened $\mathrm{Eu}(\mathrm{OTf})_{3}$ offered superior catalytic activity and provided an efficient method for accessing polyfunctionalized pyrroles 114 (Scheme 33). ${ }^{89}$ The $\mathrm{Eu}(\mathrm{OTf})_{3}$-promoted Trofimov pyrrole synthesis exhibited broad reaction scope with a wide range of aromatic, heteroaromatic and aliphatic side-chains tolerated.

An efficient and practical approach for the preparation of densely functionalized racemic and enantiopure 4,5-dihydropyrroles 117 was developed by Ghorai and co-workers. ${ }^{90}$ Thus, Nactivated aziridines 115 reacted with malononitrile 116 in the presence of $\mathrm{Sc}(\mathrm{OTf})_{3}$ via a novel domino ring-opening cyclization (Scheme 34). Markedly, $\mathrm{Sc}(\mathrm{OTf})_{3}$ additive was crucial for the activation of sulfonyl aziridine component 115 via a chelation process. The proposed mechanism proceeds via an $\mathrm{S}_{\mathrm{N}} 2$-type pathway, followed by intramolecular cyclization. 


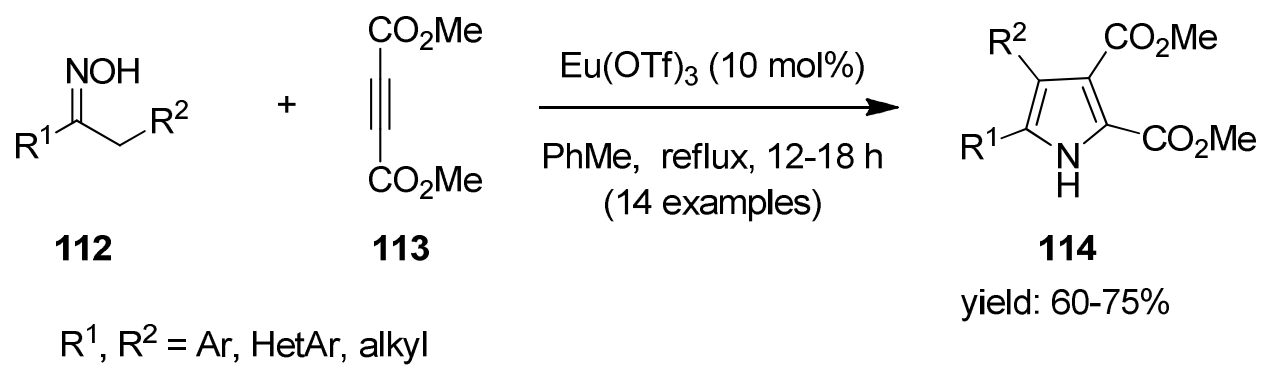

Scheme 33. $\mathrm{Eu}(\mathrm{OTf})_{3}$-promoted pyrrole synthesis.

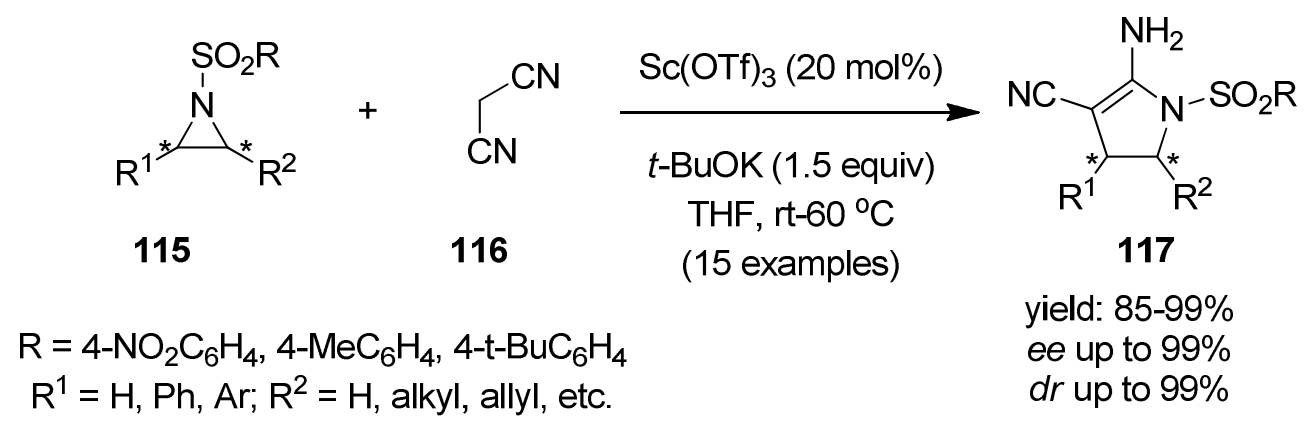

Scheme 34. Preparation of 4,5-dihydropyrroles 117 via $\mathrm{Sc}(\mathrm{OTf})_{3}$-promoted cyclization.

\section{Conclusions}

This contribution has highlighted diverse features and unique efficiency of rare earth metal triflates for a vast number of cyclization and cycloaddition reactions. The great advantages of $\mathrm{M}(\mathrm{OTf})_{3}$ reagents - their superior catalytic activity even in a presence of Lewis bases, low toxicity, easy handling, moisture and air stability, and possibility of recycling/reuse-have led to their widespread use in organic synthesis. This review will hopefully stimulate further application of rare-earth metal(III) triflates in synthesis, and the discovery of novel transformations catalyzed by these compounds will undoubtedly serve as the basis for a multitude of new and improved synthetic strategies and protocols.

\section{Acknowledgements}

The author is grateful to Dr. W. Rick Ewing and Dr. Peter W. Glunz for fruitful discussions and valuable suggestions during the preparation of this manuscript. 


\section{References}

1. Molander, G. A. Chem. Rev. 1992, 92, 29.

http://dx.doi.org/10.1021/cr00009a002

2. Baes Jr., C. F.; Mesmer, R. E. The Hydrolysis of Cations; John Wiley: New York, 1976, p 129.

3. Pol, A.; Barends, T. R.; Dietl A.; Khadem. A .F, Eygensteyn, J.; Jetten, M. S.; Op den Camp, H. J. Environ . Microbiol. 2013

http://dx.doi.org/ 10.1111/1462-2920.1249. [Epub ahead of print]

4. Thom, K. F. U.S. Patent 3615169 1971; Chem. Abstr. 1972, 76, 5436a.

5. Harrowfield, J. M.; Kepert, D .L.; Patrick, J. M.; White, A. H. Aust. J. Chem. 1983, 36, 483.

http://dx.doi.org/10.1071/CH9830483

6. Forsberg, J. H.; Spaziano, V. T.; Balasubramanian, T. M.; Liu, G. K.; Kinsley, S. A.; Duckworth, C. A.; Poteruca, J. J.; Brown, P. S.; Miller, J. L. J. Org. Chem. 1987, 52, 1017. http://dx.doi.org/10.1021/jo00382a009

7. Kobayashi, S. Chem. Lett. 1991, 2187. http://dx.doi.org/10.1246/c1.1991.2187

8. Kobayashi, S.; Hachiya, I. Tetrahedron Lett. 1992, 33, 1625. http://dx.doi.org/10.1016/S0040-4039(00)91691-5

9. Kobayashi, S.; Hachiya, I. J. Org. Chem. 1994, 59, 3590. http://dx.doi.org/10.1021/jo00092a017

10. Kobayashi, S. Synlett 1994, 689. http://dx.doi.org/10.1055/s-1994-22976

11. Marshman, R. W. Aldrichimica Acta 1995, 28, 77.

12. Steel, P. G. J. Chem. Soc., Perkin Trans. 1 2001, 2727. http://dx.doi.org/10.1039/a908189e

13. Kobayashi, S.; Manabe, K. Acc. Chem. Res. 2002, 35, 209. http://dx.doi.org/10.1021/ar000145a

14. Kobayashi, S.; Sugimura, M.; Kitagawa, H.; Hidetoshi, L.; Lam, W. W .-L. Chem. Rev. 2002, 102, 2227. http://dx.doi.org/10.1021/cr010289i

15. Luo, S.; Lizhi, Z.; Talukdar, A.; Zhang, G.; Xueling, M.; Cheng. J.-P.; Wang, P. G. MiniReview in Organic Chemistry, 2005, 2, 177. http://dx.doi.org/10.2174/1570193053544472

16. Nicolaou, K. C.; Snyder, S. A.; Montagnon, T.; Vassilikogiannakis, G. Angew. Chem. Int. Ed. 2002, 41, 1668. http://dx.doi.org/10.1002/1521-3773(20020517)41:10<1668::AID-ANIE1668>3.0.CO;2-Z 
17. Padwa, A; Pearson, W. H. (Eds) Synthetic Applications of 1,3-Dipolar Cycloaddition Chemistry Toward Heterocycles and Natural Products; Wiley-Interscience: New-York, 2002.

18. Carruthers, W. Cycloaddition Reactions in Organic Synthesis; Pergamon: Elmsford, NewYork, 1990.

19. Kobayashi, S.; Hachiya, I.; Araki, M.; Ishitani, H. Tetrahedron Lett. 1993, 34, 3755. http://dx.doi.org/10.1016/S0040-4039(00)79220-3

20. Mikami, K.; Terada, M.; Matsuzawa, H. Angew. Chem., Int. Ed. 2002, 41, 3554. http://dx.doi.org/10.1002/1521-3773(20021004)41:19<3554::AID-ANIE3554>3.0.CO;2-P

21. Kobayashi, S.; Hachiya, I.; Takahori, T.; Araki, M.; Ishitani, H. Tetrahedron Lett. 1992, 33,6815 . http://dx.doi.org/10.1016/S0040-4039(00)61783-5

22. Kobayashi, S.; Hachiya, I.; Araki, M.; Ishitani, H. Tetrahedron Lett. 1993, 34, 3755. http://dx.doi.org/10.1016/S0040-4039(00)79220-3

23. Inokuchi, T.; Okano, M.; Miyamoto, T. J. Org. Chem. 2001, 66, 8059 http://dx.doi.org/10.1021/jo010575u

24. Kobayashi, S.; Hachiya, I.; Ishitani, H.; Araki, M. Tetrahedron Lett. 1993, 34, 4535. http://dx.doi.org/10.1016/0040-4039(93)88078-W

25. Kobayashi, S.; Araki, M.; Hachiya, I. J. Org. Chem. 1994, 59, 3758. http://dx.doi.org/10.1021/jo00093a004

26. Sudo, Y.; Shirasaki, D.; Harada, S.; Nishida, A. J. Am. Chem. Soc. 2008, 130, 12589. http://dx.doi.org/10.1021/ja804430n

27. Harada, S.; Toudou, N.; Hiraoka, S.; Nishida, A. Tetrahedron Lett. 2009, 50, 5652. http://dx.doi.org/10.1016/j.tetlet.2009.07.110

28. Hiraoka, S.; Harada, S.; Nishida, A. J. Org. Chem. 2010, 75, 3871. http://dx.doi.org/10.1021/jo1003746

29. Harada, S.; Morikawa, T.; Nishida, A. Org. Lett. 2013, 15, 5314. http://dx.doi.org/10.1021/ol402559z

30. Nishina,Y.; Kida, T.; Ureshino, T. Org. Lett. 2011, 13, 3960. http://dx.doi.org/10.1021/ol201479p

31. Sibi, M. P.; Nie, X.; Shackleford, J. P.; Stanley, L. M.; Bouret, F. Synlett 2008, 2655. http://dx.doi.org/10.1055/s-0028-1083438

32. Shiramizu, M.; Toste, D. F. Chem. Eur. J. 2011, 17, 12452. http://dx.doi.org/10.1002/chem.201101580

33. Boger, D. L.; Weinreb, S. M. Organic Chemistry; Hetero Diels-Alder Methodology in Organic Synthesis, Vol. 47; Academic Press: San Diego, 1987.

34. Ma, S. (Ed.) Handbook of Cyclization Reactions; Wiley-VCH: Weinheim, 2010.

35. Tietze, L. F.; Kettschau, G. Top. Curr. Chem. 1997, 189, 1. http://dx.doi.org/10.1007/BFb0119240

36. Corey, E. J. Angew. Chem., Int. Ed. 2002, 41, 1650. 
http://dx.doi.org/10.1002/1521-3773(20020517)41:10<1650::AID-ANIE1650>3.0.CO;2-B

37. Shao, J.; Yang, J-S. J. Org. Chem. 2012, 77, 7891.

http://dx.doi.org/10.1021/jo3010777

38. Xu, Z.; Liu, L.; Wheeler, K.; Wang, H. Angew. Chem. Int. Ed. 2011, 50, 3484.

http://dx.doi.org/10.1002/anie.201100160

39. Tiseni, P. S.; Peters, R. Org. Lett. 2008, 10, 2019.

http://dx.doi.org/10.1021/o1800742d

40. Zhu, Y.; Xie, M.; Dong, S.; Zhao, X.; Lin, L.; Liu, X.; Feng, X. Chem. Eur. J. 2011, 17, 8202.

http://dx.doi.org/10.1002/chem.201100520

41. Mo, J.; Chen, X.; Chi, Y. R. J. Am. Chem. Soc. 2012, 134, 8810.

http://dx.doi.org/10.1021/ja303618z

42. Povarov, L. S. Russ. Chem. Rev. 1967, 36, 656.

http://dx.doi.org/10.1070/RC1967v036n09ABEH001680

43. Kouznetsov, V. V. Tetrahedron 2009, 65, 2721.

http://dx.doi.org/10.1016/j.tet.2008.12.059

44. Truong, P. M.; Mandler, M. D.; Zavalij, P. Y.; Doyle, M. P. Org. Lett. 2013, 15, 3278. http://dx.doi.org/10.1021/o1401308d

45. Kondrat'eva, G. Ya.; Khim. Nauka Prom-st. 1957, 2, 666.

46. Sabot, C.; Oueis, E.; Brune, X.; Renard, P.-Y. Chem. Commun. 2012, 48, 768. http://dx.doi.org/10.1039/c1cc16562c

47. K. Nagaiah, K.; Venkatesham, A.; Srinivasa Rao, R.; Saddanapu. V.; Yadav, J. S.; Basha, S. J.; Sarma, A. V. S.; Sridhar, B.; Addlagatta, A. Bioorg. Med. Chem. Lett. 2010, 20, 3259. http://dx.doi.org/10.1016/j.bmcl.2010.04.061

48. Chen, Z.; Lin, L.; Chen, D.; Li, J.; Liu, X.; Feng, X. Tetrahedron Lett. 2010, 51, 3088. http://dx.doi.org/10.1016/j.tetlet.2010.04.009

49. Xie, M.; Chen, X.; Zhu, Y.; Gao, B.; Lin, L.; Liu, X.; Feng, X. Angew. Chem. Int. Ed. 2010, 49, 3799.

http://dx.doi.org/10.1002/anie.201000590

50. Wang, X.-S.; Zhou, J.; Yang, K.; Yao, C.-S. Tetrahedron Lett. 2010, 51, 5721. http://dx.doi.org/10.1016/j.tetlet.2010.08.074

51. Wood, J.; Bagi, C. M.; Akuche, C.; Bacchiocchi, A.; Baryza, J.; Blue, M. L.; Brennan, C.; Campbell, A. M.; Choi, S.; Cook, J. H.; Conrad, P.; Dixon, B. R.; Ehrlich, P. P.; Gane, T.; Gunn, D.; Joe, T.; Johnson, J. S.; Jordan, J.; Kramss, R.; Liu, P.; Levy, J.; Lowe, D. B.; McAlexander, I.; Natero, R.; Redman, A. M.; Scott, W. J.; Town, C.; Wang, M.; Wang, Y.; Zhang, Z. Bioorg. Med. Chem. Lett. 2006, 16, 4965.

http://dx.doi.org/10.1016/j.bmcl.2006.06.041

52. Roy, S.; Reiser, O. Angew. Chem. Int. Ed. 2012, 51, 4722. http://dx.doi.org/10.1002/anie.201107831

53. Gothelf, K. V.; Jorgensen, K. A. Chem. Rev. 1998, 98, 863. 


\section{http://dx.doi.org/10.1021/cr970324e}

54. Coldham, I.; Hufton, R. Chem. Rev. 2005, 105, 2765.

http://dx.doi.org/10.1021/cr040004c

55. Pellissier, H. Tetrahedron 2007, 63, 3235.

http://dx.doi.org/10.1016/j.tet.2007.01.009

56. Chen, Z.; Wei, L.; Zhang, J. Org. Lett. 2011, 13, 1170.

http://dx.doi.org/10.1021/o12000292

57. Li, L.; Zhang, J. Org. Lett. 2011, 13, 5490.

58. Ding, Q.; Wang, Z.; Wu, J. Tetrahedron Lett. 2009, 50, 198.

http://dx.doi.org/10.1016/j.tetlet.2008.10.121

59. Hu, B.; Zhu, J.; Xing, S.; Fang, J.; Du, D.; Wang, Z. Chem. Eur. J. 2009, 15, 324.

http://dx.doi.org/10.1002/chem.200801990

60. Xing, S.; Pan, W.; Liu, C.; Ren, J.; Wang, Z. Angew. Chem. Int. Ed. 2010, 49, 3215. http://dx.doi.org/10.1002/anie.201000563

61. Tiefenbacher, K.; Mulzer, J. Angew. Chem. Int. Ed. 2008, 47, 2548. http://dx.doi.org/10.1002/anie.200705303

62. Hu, B.; Xing, S.; Ren, J.; Wang, Z. Tetrahedron 2010, 66, 5671. http://dx.doi.org/10.1016/j.tet.2010.05.057

63. Zhu, Z.; Fang, J.; Liu, Y.; Ren, J.; Wang, Z. Angew. Chem. Int. Ed. 2013, 52, 2032. http://dx.doi.org/10.1002/anie.201206484

64. Parsons, A. T.; Johnson, J. S. J. Am. Chem. Soc. 2009, 131, 14202. http://dx.doi.org/10.1021/ja906755e

65. Moustafa, M. M. A. R.; Pagenkopf, B. L. Org. Lett. 2010, 12, 4732. http://dx.doi.org/10.1021/ol102062t

66. Moustafa, M. M. A. R.; Stevens, A. C.; Machin, B. P.; Pagenkopf, B. L. Org. Lett. 2010, 12, 4736 . http://dx.doi.org/10.1021/ol102063f

67. Stevens, A. C.; Palmer, C.; Pagenkopf, B. L. Org. Lett. 2011, 13, 1528. http://dx.doi.org/10.1021/ol200220d

68. Mori, K.; Sueoka, S.; Akiyama, T. J. Am. Chem. Soc. 2011, 133, 2424. http://dx.doi.org/10.1021/ja110520p

69. Mori, K.; Sueoka, S.; Akiyama, T. Chem. Lett. 2011, 40, 1386. http://dx.doi.org/10.1021/ja110520p

70. McQuaid, K. M.; Long, J. Z.; Sames, D. Org. Lett. 2009, 11, 2972. http://dx.doi.org/10.1021/o1900915p

71. Murarka, S.; Zhang, C.; Konieczynska, M. D.; Seidel, D. Org. Lett. 2009, 11, 129. http://dx.doi.org/10.1021/o1802519r

72. Renaud, P.; Sibi, M. P., Eds. Radicals in Organic Synthesis; Wiley-VCH: Weinheim, 2001; Vol. 2. http://dx.doi.org/10.1002/9783527618293 
73. Renaud, P.; Gerster, M. Angew. Chem. Int. Ed. 1998, 37, 2562.

http://dx.doi.org/10.1002/(SICI)1521-3773(19981016)37:19<2562::AID-

ANIE2562>3.0.CO;2-D

74. Yu, J.-D.; Ding, W.; Lian, G.-Y.; Song, K.-S.; Zhang, D.-W.; Gao, X.; Yang, D. J. Org.

Chem. 2010, 75, 3232.

http://dx.doi.org/10.1021/jo100139u

75. Lu, Z.; Shen, M.; Yoon, T. P. J. Am. Chem. Soc. 2011, 133, 1162.

http://dx.doi.org/10.1021/ja107849y

76. Tran, V.; G. Minehan, T. G. Org. Lett. 2012, 14, 6100.

http://dx.doi.org/10.1021/ol303026v

77. B. V. Subba Reddy, B. V.; Borkar, P.; Chakravarthy, P. P.; Yadav, J. S.; Gree, R. Tetrahedron Lett. 2010, 51, 3412.

78. Moebius, D. C.; Kingsbury, J. S. J. Am. Chem. Soc. 2009, 131, 878.

http://dx.doi.org/10.1021/ja809220j

79. Wommack, A. J.; Moebius, D. C.; Travis, A. L.; Kingsbury, J. S. Org. Lett. 2009, 11, 3202. http://dx.doi.org/10.1021/o19010932

80. Rendina, V. L.; Moebius, D. C.; Kingsbury, J. S. Org. Lett. 2011, 13, 2004. http://dx.doi.org/10.1021/ol200402m

81. Rendina, V. L.; Kaplan, H. Z.; Kingsbury, J. S. Synthesis 2012, 44, 686. http://dx.doi.org/10.1055/s-0031-1289650

82. Liu, L.; Sarkisian, R.; Deng, Y.; Wang, H. J. Org. Chem. 2013, 78, 5751. http://dx.doi.org/10.1021/jo400578m

83. Veits, G. K.; Read de Alaniz, J. Tetrahedron 2012, 68, 2015. http://dx.doi.org/10.1021/jo400578m

84. Veits, G. K.; Wenz, D. R.; Read de Alaniz, J. Angew. Chem. Int. Ed. 2010, 49, 9484. http://dx.doi.org/10.1002/anie.201005131

85. Palmer, L. I.; Read de Alaniz, J. Angew. Chem., Int. Ed. 2011, 50, 7167. http://dx.doi.org/10.1002/anie.201102102

86. Wenz, D. R.; Read de Alaniz, J. Org. Lett. 2013, 15, 3250. http://dx.doi.org/10.1021/ol401248p

87. Palmer, L. I.; Read de Alaniz, J. Org. Lett. 2013, 15, 476. http://dx.doi.org/10.1021/o1303263q

88. Trofimov, B. A.; Sobenina, L. N.; Demenev, A. P.; Mikhaleva, A. I. Chem. Rev. 2004, 104, 2481. http://dx.doi.org/10.1021/cr020100i

89. Madabhushi, S.; Vangipuram, V. S.; Reddy Mallu, K. K.; Chinthala, N.; Beerama, C. R. Adv. Synth. Catal. 2012, 354, 1413. http://dx.doi.org/10.1002/adsc.201200036

90. Ghorai, M. K.; Tiwari, D. P. J. Org. Chem. 2013, 78, 2617. http://dx.doi.org/10.1021/jo302815m 


\section{Author's Biography}

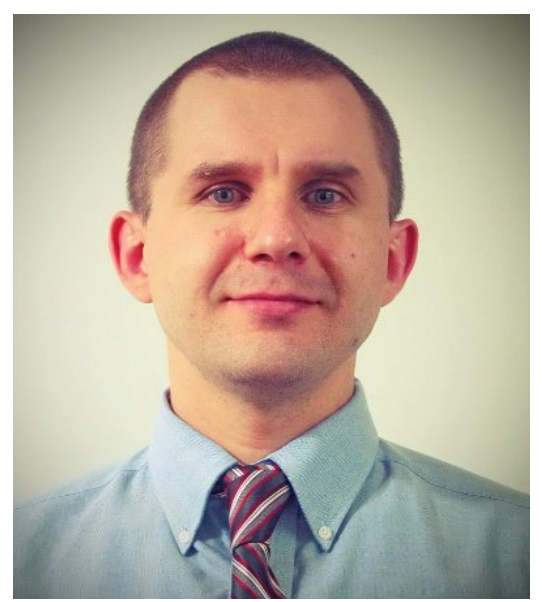

Uladzimir (Vladimir) Ladziata was born in Pinsk, Belarus. In 2003 he graduated from Belarusian State University (Minsk) with a M.Sc. degree in Medicinal Chemistry. In 2004 he joined the research group of Professor Viktor V. Zhdankin at the University of Minnesota Duluth, where his research was focused on the development of new hypervalent iodine(V) reagents as useful synthetic tools for organic and medicinal chemistry. In 2006 he started his career at Bristol-Myers Squibb, where he is currently a research scientist in Discovery Chemistry. His research interests include rational drug design and applications of new methodologies towards synthesis of biologically active compounds. 